\title{
Design, Manufacture and Test of Cryotank Components
}

Douglas A McCarville, Boeing, Bonney Lake, WA, United States

Juan C Guzman and Alexandra K Dillon, Boeing, Seattle, WA, United States

Justin R Jackson, NASA Marshall Space Flight Center, Huntsville, AL, United States

Jordan 0 Birkland, Boeing, Lynnwood, WA, United States

\begin{tabular}{llr}
$\mathbf{1}$ & Introduction & 2 \\
$\mathbf{2}$ & Composite Cryotank Background & 2 \\
2.1 & Cryotank Historic Overview & 3 \\
2.2 & CCTD Program Overview & 7 \\
$\mathbf{3}$ & Boeing's Tank Design and Manufacturing Approach & 8 \\
3.1 & Configuration Overview & 8 \\
3.2 & Materials & 10 \\
3.3 & Tooling Approach & 11 \\
3.4 & Manufacturing Approach & 12 \\
$\mathbf{4}$ & Tank Development and Build Activities & 12 \\
4.1 & Process Development, Building Block Activities & 12 \\
4.2 & 2.4 m Precursor & 13 \\
4.3 & 5.5 m Full-Scale Tank & 17 \\
$\mathbf{5}$ & Tank Testing & 21 \\
5.1 & Test Criteria and Goal & 22 \\
5.2 & Test Results & 23 \\
$\mathbf{6}$ & Future Recommendations & 26 \\
$\mathbf{7}$ & Summary & 26 \\
References & & 26 \\
Further Reading & & 27 \\
Relevant Websites & 27 \\
\hline
\end{tabular}

\section{Abbreviations}

ADC Advanced Development Center

AE Acoustic emission

AFRL Air Force Research Laboratory

AMP Automated material placement

AUSS Automated ultrasonic scanning systems

CCTD Composite cryotank technology development

C/E Carbon/epoxy

CLTS Cryogenic linear temperature sensor

CNC Computer numerical controlled

CTS Composite tank-set

3D 3-Dimensional

DAC Douglas Aircraft Company

DARPA Defense advanced research projects agency

DoD Department of defense

DUP Design ultimate pressure

EELV Evolved expendable launch vehicles

FAST Future-responsive Access to Space Technologies

FEA Finite element analysis

FEM Finite element model

GCDP Game Changing Development Program

GFI Government-Furnished Information

$\mathrm{GH}_{2}$ Gaseous hydrogen

GHe Gaseous helium

HC Honeycomb

HTOL Horizontal take-off and landing
JI Janicki Industries

LEO Low Earth orbit

$\mathrm{LH}_{2}$ Liquid hydrogen

LM Lockheed Martin

LOX Liquid oxygen

MDC McDonnell Douglas Corporation

MDP Maximum design pressure

MDU Manufacturing demonstration units

MRL Manufacturing readiness level

MSFC George C. Marshall Space Flight Center

NASA National Aeronautics and Space Administration

NASP National aerospace plane

NBS National Bureau of Standards

NC Numerically controlled

NCAM National Center for Advanced Manufacturing

NDI Nondestructive inspection

NG Northrup Grumman

NGLT Next generation launch technology

OHME Overhead moving equipment

OLT Optical laser templates

OML Outside mold line

OoA Out-of-autoclave

OSP Orbital space plane

OTV Orbital test vehicles

PE Pulse-echo

prepreg Pre-impregnated 
SAF Skirt alignment fixture

SBKF Shell buckling knockdown factor

SDIO Strategic Defense Initiative Organization

SGT Super guppy turbine

SHMS Structural health monitoring system

SLI Space Launch Initiative

SLS Space Launch System

SSTO Single stage to orbit
STT Slit-tape tow

TRL Technology readiness level

TTU Through-transmission ultrasonic

UDF Ultimate design factor

Uni-tape Uni-directional tape

VCP VERICUT composite programming

VTOL Vertical takeoff and landing

\section{Nomenclature}

$\mathrm{N}_{2}$ Nitrogen

Tg Glass transition temperature

\section{Introduction}

On the composite cryotank technology development (CCTD) project, the Boeing Company built two cryotanks as a means of advancing technology and manufacturing readiness levels (TRL and MRL) and lowering the risk of fabricating full-scale fuel containment vessels. ${ }^{1}$ CCTD focused on upper stage extended duration applications where long term storage of propellants is required. The project involved the design, analysis, fabrication, and test of manufacturing demonstration units (MDU), a $2.4 \mathrm{~m}$ (precursor) and a $5.5 \mathrm{~m}$ composite cryotank. Key design features included one-piece wall construction to minimize overall weight (eliminating the need for a bellyband joint), 3-dimensionally (3D) reinforced y-joint material to alleviate stress concentrations at the tank to skirt interface and a purge-able fluted core skirt to carry high axial launch loads. The tanks were made with OoA curing pre-impregnated (prepreg) carbon/epoxy (C/E) slit-tape tow (STT) that contained thin micro-crack resistant plies in the tank wall center to impede permeation.

The tanks were fabricated at Boeing's Seattle-based Advanced Development Center (ADC) using RAFP and multipiece breakdown tooling. The tooling was designed and built by Janicki Industries (JI) at Sedro Woolley, Washington. Tank assemblage consisted of co-bonded dome covers, one-piece fluted core skirts and mechanical fastened cover/sump. Ultrasonic inspection was performed after every cure or bond and a structural health monitoring system (SHMS) was installed to identify potential impact damage events (in-process and/or during transportation). The tanks were low temperature tested at NASA's George C. Marshall Space Flight Center (MSFC) in Huntsville, Alabama. The testing, which consisted of a sequence of fill/drain pressure and thermal cycles using $\mathrm{LH}_{2}$, was successfully concluded in 2012 on the $2.4 \mathrm{~m}$ tank and in 2014 on the $5.5 \mathrm{~m}$ tank. Structural, thermal, and permeation performance data was obtained. ${ }^{2}$ Critical design features and manufacturing advancements, which helped to validate $25 \%$ weight and $30 \%$ cost reduction projections, were matured. These advancements will help to guide future composite tank integration activities on next generation long duration aircraft and space launch vehicles. Because CCTD addressed innovative design features, heavy lift size scale-up, multipiece captured tooling, new generation automated material placement (AMP) equipment and OoA materials, this chapter should be of interest to educators, students and manufacturers of composite hardware and flight vehicles.

\section{Composite Cryotank Background}

NASA is exploring advanced composite materials and processes to reduce the overall cost and weight of $\mathrm{LH}_{2}$ and liquid oxygen (LOX) cryotanks while maintaining reliability levels that will enable human space exploration to destinations beyond low Earth orbit (LEO), such as the moon, near-Earth asteroids, and Mars.

For more than 50 years, metal cryogenic tanks have carried the $\mathrm{LH}_{2}$ and $\mathrm{LOX}$ necessary to launch men and payloads into space. Typically about $70 \%$ of the dry mass of a launch vehicle consists of the fuel and oxidizer tanks. Therefore, if composite materials were used on a new launch system, the overall weight could be reduced by as much as $30 \%$ when compared to an aluminum craft. Still, technology challenges, such as $10 \mathrm{~m}$ scale-up, long duration permeation control and complex joint load transfer, have kept NASA from incorporating composite cryotanks into new generation launch vehicles, like the new Space Launch System (SLS) (Fig. 1). ${ }^{3}$

One of the greatest roadblocks that NASA faces when incorporating new technologies into their products is bridging the TRL/MRL gap between early development (2-3: feasibility) and flight incorporation (8-9: launch and operations) (Fig. 2). ${ }^{4}$ The intent of the CCTD program was to bridge a portion of this maturity gap by building and testing flight representative full-scale composite tanks (5-6: demonstrated). During Phase 1 of the effort, contractors were asked to identify scale-up risk areas (e.g., performance, cost, schedule, manufacturing and inspection) and propose ways to reduce these risks during Phase 2. In so doing, it was reasoned that the evolved low weight and cost tank designs and manufacturing methods would support human space exploration activities beyond LEO (e.g., moon, near-earth asteroids, and Mars). NASA contracted large system integrators (ATK Launch Systems, The Boeing Company, Lockheed Martin (LM), and Northrop Grumman Corporation) with designing 


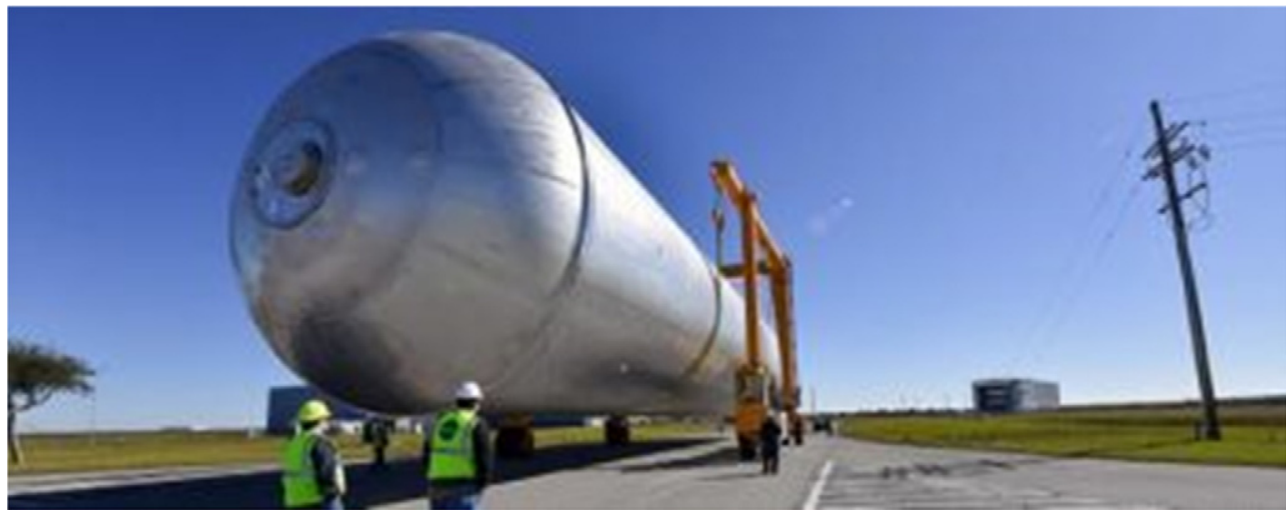

Fig. 1 Space Launch System (SLS) metal cryotank. Reproduced from Vickers, J., 2013. Composites Australia Conference composite cryotank projects Structures for launch vehicles. In: Composites Australia Conference and Trade Show. Melbourne, Australia.

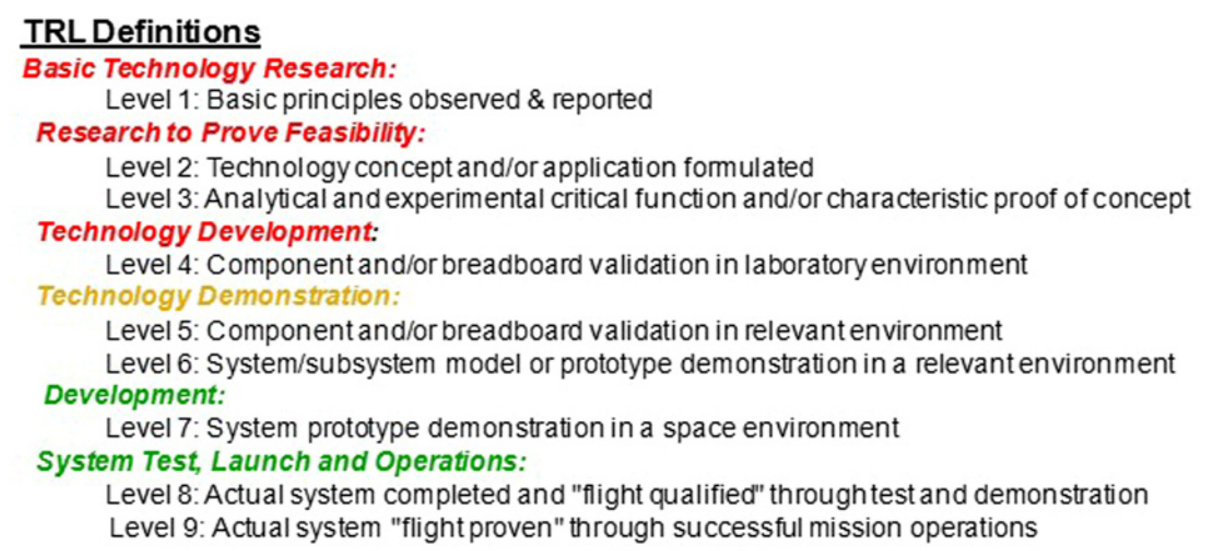

\begin{tabular}{|c|c|c|}
\hline Level & MRLDefinition & \\
\hline 3 & Manu facturing process development. & CombinedMRL/TRL Levels \\
\hline $\begin{array}{l}4 \\
5\end{array}$ & $\begin{array}{l}\text { Critical manu facturing processes prototyped. } \\
\text { Prototype manufacturing system. }\end{array}$ & $\square$ 1-4 Concept Refinement/Laboratory \\
\hline 6 & Manu facturing process maturity demonstration. & $\square$ 5-6 Technology-Mfg Demonstrated \\
\hline 7 & Manu facturing processes proven. & $\square 7-10$ Demo'd in Environment or Deployed \\
\hline $\begin{array}{l}8 \\
9\end{array}$ & $\begin{array}{l}\text { Production manufacturing identified. } \\
\text { Manufacturing process deployed. }\end{array}$ & \\
\hline
\end{tabular}

Fig. 2 Technology and manufacturing readiness levels (MRLs).

composite cryotanks with features and strain levels applicable to $10 \mathrm{~m}$, but to build at a 2.4 and $5.5 \mathrm{~m}$ scale (Fig. 3). This cost containment strategy ensured that the developed technologies addressed near term (next 20 years) heavy-lift vehicle scale-up while fitting within existing infrastructure (e.g., autoclaves, ovens, AMP equipment and in-plant transportation systems). It should be noted that $5.5 \mathrm{~m}$ is comparable to existing evolved expendable launch vehicles (EELV) like Atlas, Delta and Falcon (Fig. 4). ${ }^{5}$ Identified future spin-off applications include 1st and 2nd stage $\mathrm{LH}_{2}$ and LOX tanks for heavy launch systems like SLS, in-space propulsion systems, on-orbit propellant depots, landers and long duration aircraft.

\subsection{Cryotank Historic Overview}

Over the past three decades, a variety of composite cryotank programs have been sponsored by NASA, Defense Advanced Research Projects Agency (DARPA), and the Air Force as a means of reducing launch vehicle weight and increasing payload capacity. Each of these projects has had some success but there have been challenges that made these agencies reluctant to incorporate composite cryotanks into launch platforms. As a historic overview of the topic, the following items will be covered for several key cryotank programs: (1) program summary/purpose, (2) technological advancements, (3) challenges encountered, (4) risk mitigation activities, (5) program ending status, and (6) go forward lessons learned. 


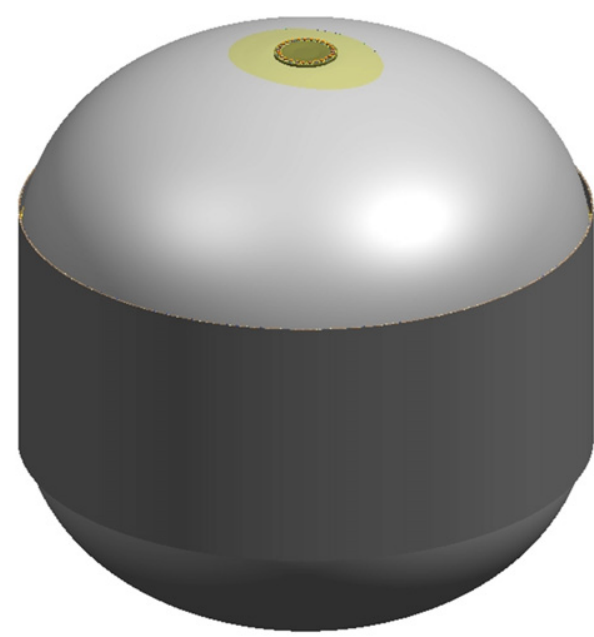

Phase I: 10 m Diameter Reference Tank

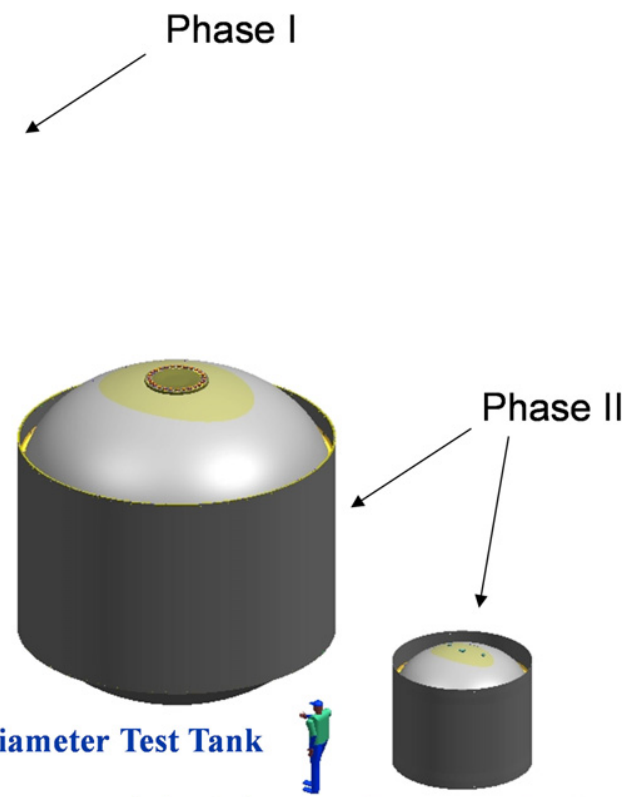

2.4 m Diameter Precursor Tank

Fig. 3 Composite cryotank technology development (CCTD) tank scales.

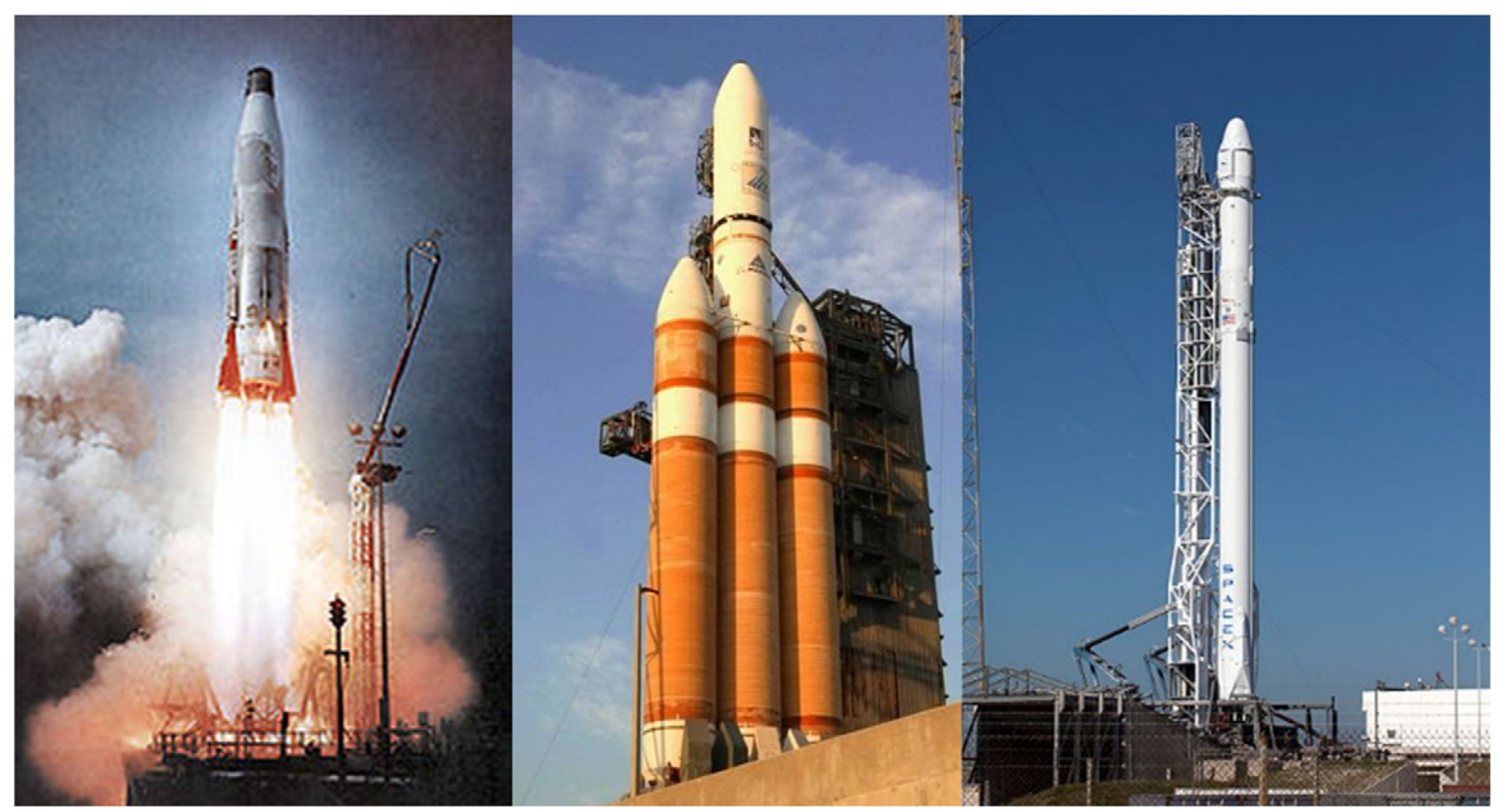

Fig. 4 Existing expendable launch vehicles: Atlas, Delta, and Falcon.

One of the first US programs that had a strong need for composite tanks, in order to meet performance goals, was the National Aerospace Plane (NASP), X-30. This program started during the Reagan administration, in 1982. NASP was a DARPA-funded feasibility study for a single stage to orbit (SSTO) spaceplane. ${ }^{6}$ This scramjet propelled concept vehicle was envisioned to achieve speeds of up to Mach 25. This required tank structures that could hold pressurized liquid cryogenic fluids while handling aerothermal heating. Due to the vehicles projected flight envelope, the tanks were a major portion of the overall craft's structure. There was an aerospace industry-wide competition for NASP. Participants assumed that the first company to produce a good composite $\mathrm{LH}_{2}$ tank might have a leg up in winning a flight vehicle contract. In 1987 McDonnell Douglas Corporation (MDC) completed their first composite cryotank. Their concept was a conformal load bearing structure. This design presented many 
design, tooling and materials challenges. To meet high temperature requirements, MDC evaluate the use of a thermoplastic graphite reinforced material which was under evaluation by the National Bureau of Standards (NBS) because of its high glass transition temperature ( $\mathrm{Tg}$ is the temperature at which the matrix resin softens during reheating). High use temperature reduces the need for thermal protection and thus can reduce the overall weight of a cryotank system. High temperature processing, tooling, scale-up and cost challenges proved a major hurdle that eventually led MDC to build the final test component using a 350F amine-curing toughened epoxy. During this activity, MDC was the first company to successfully perform low temperature $\mathrm{LH}_{2}$ fill/drain tests on a large composite cryotank. By demonstrating low leak level operation, the tank advanced design, tooling and manufacturing levels. ${ }^{7}$ The NASP program was canceled in 1988, not due to the cryotank, but rather due to the scramjet's immaturity/risk.

In 1991, MDC, in conjunction with the Department of Defense's (DoD) Strategic Defense Initiative Organization (SDIO), undertook the DC-X program to create a technology demonstrator for a SSTO vehicle that could be quickly/cost effectively reflown. The initial vertical takeoff and landing (VTOL) Delta Clipper design used an aluminum $\mathrm{LH}_{2}$ fuel tank but this later changed to composites as requirements tightened. In 1994, NASA took over direction of the program, renamed it DC-XA and added additional design and performance goals. DC-XA construction and technology advancement activities built on Douglas Aircraft Company (DAC) (later purchased by MD) S-IVB $\mathrm{LH}_{2} / \mathrm{LOX}$ work for Saturn V upper-stages and the previously discussed NASP activities. $^{8}$ The DC-XA tank was fabricated in two halves using a carbon/epoxy material. The halves were spliced together with a bonded belly-band joint. Like some Saturn V tanks, the DC-XA tank was insulated internally. The 1/3 scale DC-XA $2.4 \mathrm{~m}$ diameter tank became the first composite cryotank to be used on a flight vehicle (Fig. 5). The DC-XA flew four times before the Delta Clipper was damaged during landing. The program was canceled shortly thereafter.

Also in the 1990s, the US government funded a SSTO Space Launch Initiative (SLI) called reusable launch vehicle (RLV) X-33. The X-33 program was created to develop critical technologies for horizontal take-off and landing (HTOL). Similar to NASP, there was an industry-wide competition for a technology demonstrator that was to pave the way for a large-scale Venture Star flight test vehicle. Challenging weight requirements drove the need for a composite cryotank. LM won the contract for a half-scale unmanned demonstrator and chose to build a $3 \mathrm{~m}$ multilobed honeycomb (HC) sandwich structure tank using a carbon/epoxy prepreg material. As with DC-XA, the program had aggressive performance, cost and timeline goals. Therefore, LM chose a mature material (initially developed for fighter jets) with an existing data base for the cryotank. The multilobed HC tank proved difficult to fabricate, requiring advanced fastening, bonding and tooling methodologies. In 1999 LM's X-33 tank was pressure cycled with $\mathrm{LH}_{2}$, during which the outer skin delaminated from the HC. After a detailed failure root cause analysis, it was ascertained that micro-cracking of the composite laminate allowed some of the $\mathrm{LH}_{2}$ to permeate into the $\mathrm{HC}$ and outside air to cryo-pump into the sandwich structure. Subsequently, since the HC did not have a vent path and portions of the film adhesive tank wall to the HC bond were weaker than designed, when the frozen air expanded during re-heat structural failure resulted (Fig. 6).

X-33 had aggressive launch goals which did not allow time for a building block technology maturation approach. The program went from coupon level test to full-scale production with minimal subcomponent testing and MDU's. After test failure the
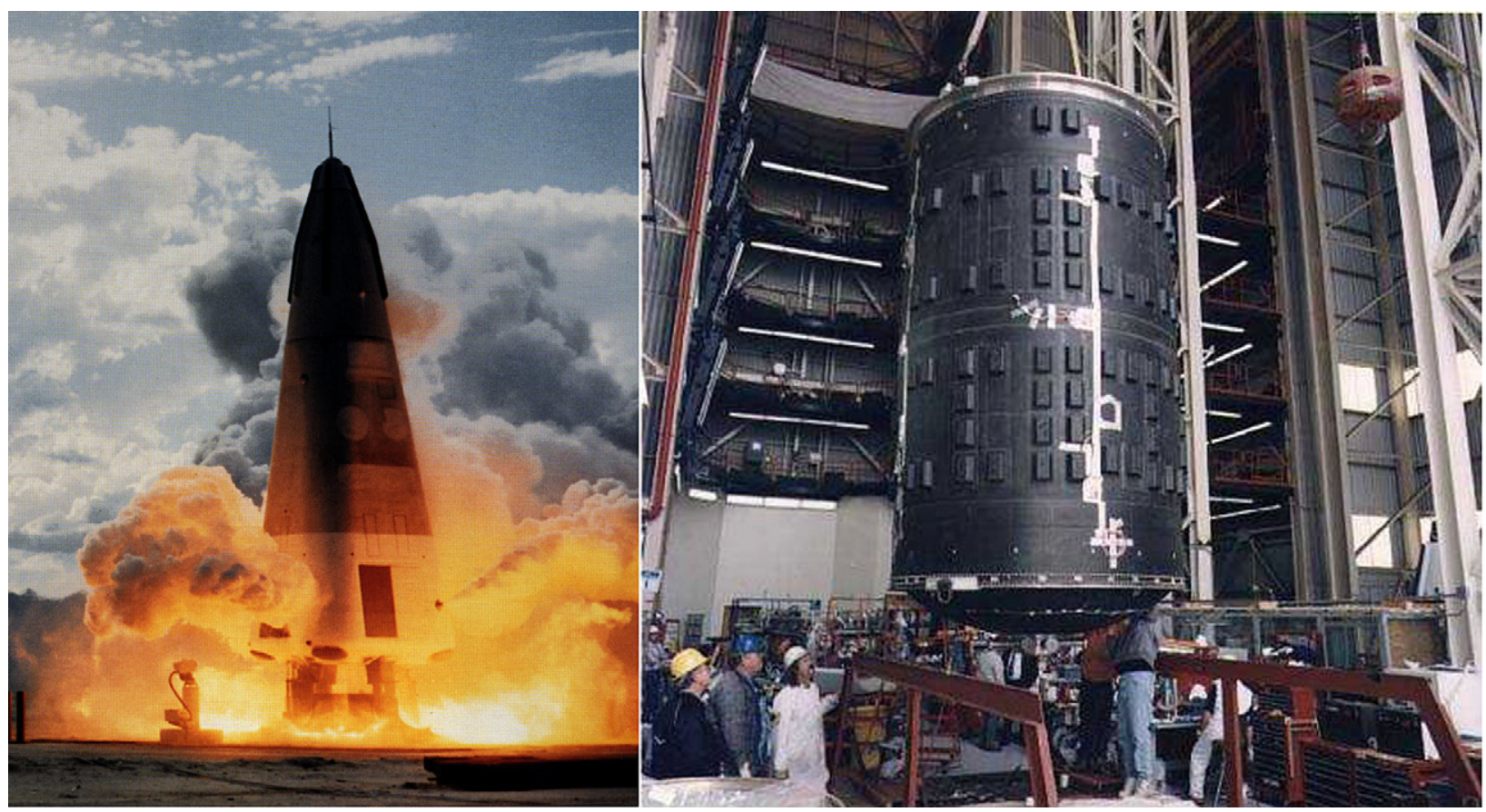

Fig. 5 DC-XA composite cryotank. 

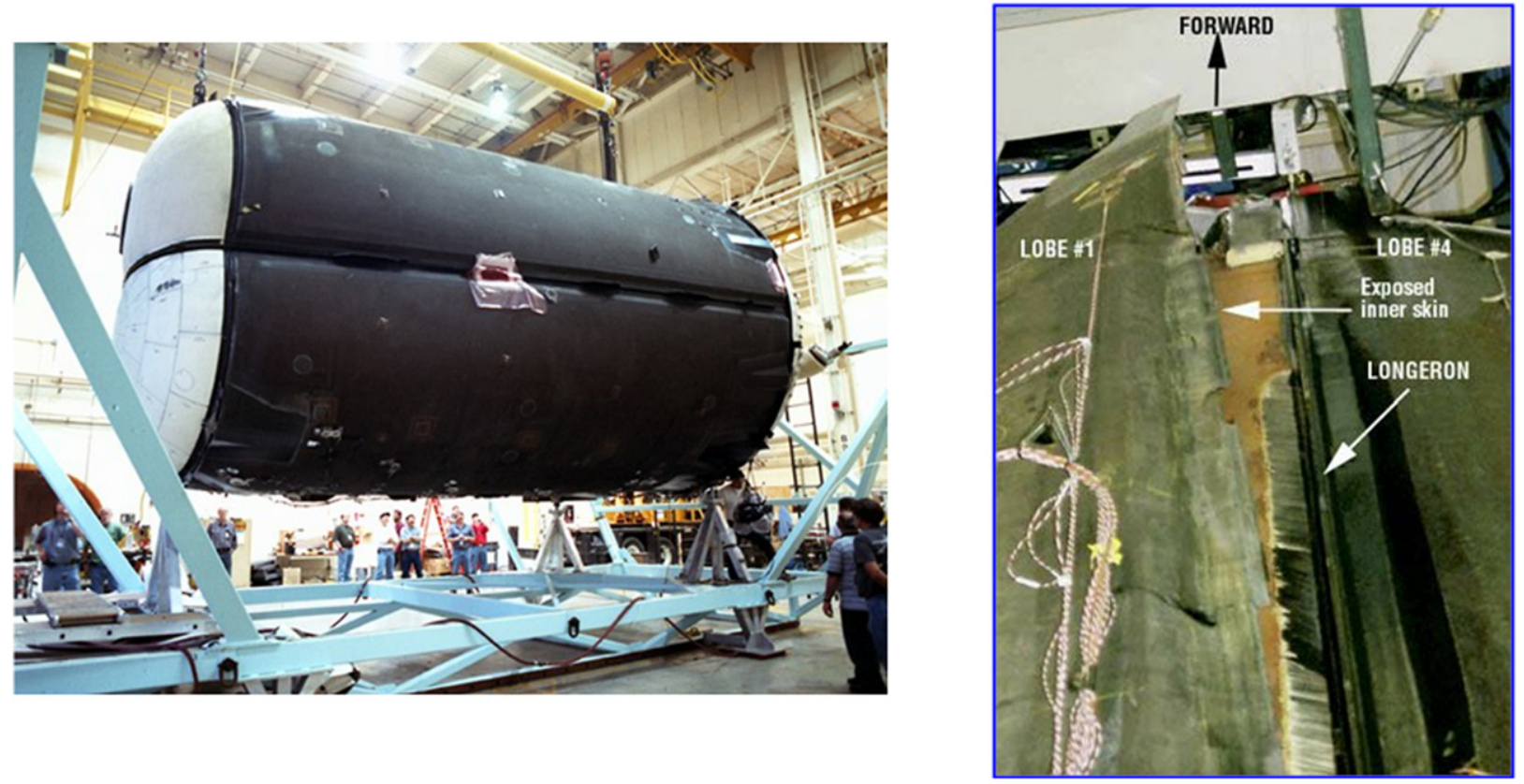

Fig. 6 X-33 composite liquid hydrogen $\left(\mathrm{LH}_{2}\right)$ tank failure.

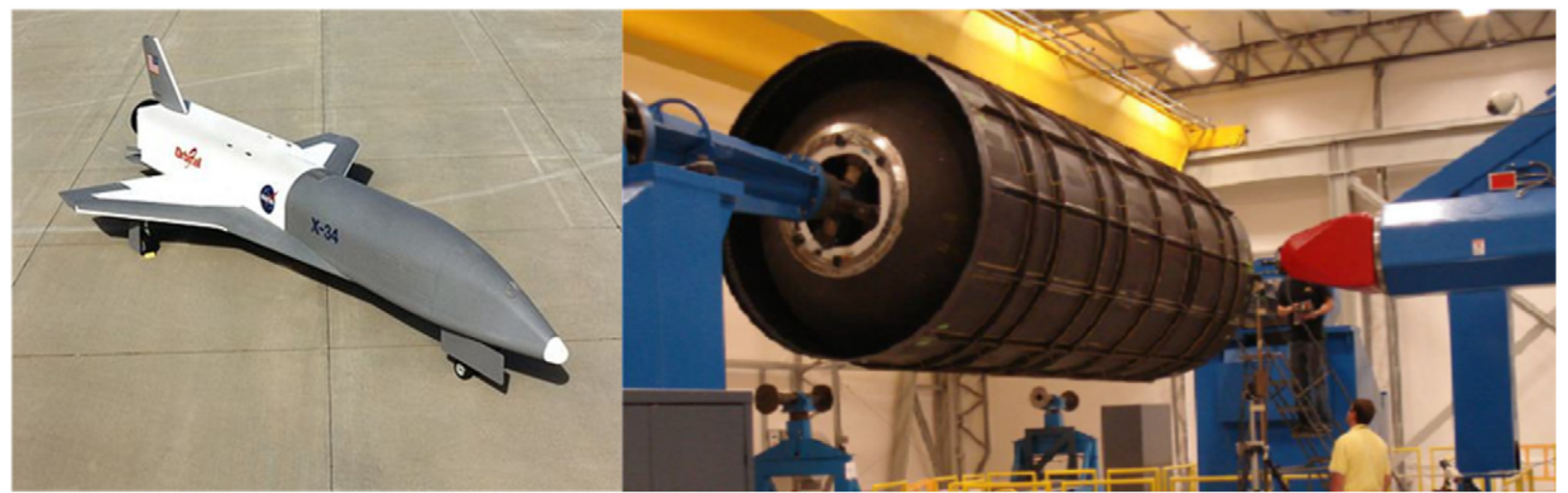

Fig. 7 X-34 Fastrac and LM liquid oxygen (LOX)/kerosene tank.

program was canceled, not totally due to the tank. There were other technology challenges/risks (e.g., an aero-spike engine, HTOL infrastructure and overall vehicle mass) that contributed to the decision. The test investigation team noted that X-33's tank failure did not invalidate the use of composite materials for cryogenic tanks. Rather, methods of limiting permeation and dissipating trapped gases needed further development and maturation. Also, it should be noted that at that time of the RLV program activities, the industry did not posess large enough autoclaves to cure full-scale prepreg tanks in one-piece.

Although X-33 may have reduced confidence in the use of composites for cryotanks, it did not diminish the need. Subsequently, additional RLV programs, namely orbital test vehicles (OTV) X-34 and X-37 and Next Generation Launch Technology (NGLT), continued to evaluate composite cryotanks.

Orbital Science's X-34 was a horizontal landing winged lifting body vehicle intended to be a low cost testbed for demonstrating key technologies. It was planned to be rapidly deployable and reused, up to 25 times per year. The X-34 had a LOX/kerosene-based propulsion system (the low cost NASA developed disposable Fastrac engine) that has performance goals that drove the need for a composite tank. ${ }^{10}$ As part of the Air Force Research Laboratory (AFRL) Future-responsive Access to Space Technologies (FAST) program, LM developed a liner-less composite tank with external stiffening and fabricated it at the NASA MSFC (Fig. 7). ${ }^{11}$ In conjunction, extensive LOX - C/E compatibility studies were performed. The tank was successfully tested by conducting low temperature flow and fill-drain pressure cycles. The X-34 program, and associated Fastrac engine development, were canceled in 2001 prior to autonomous flight due to cost containment issues. ${ }^{12}$ The effort was replaced by the Boeing built X-37/40 orbital space plane (OSP) (Fig. 8). The X-37, which uses metallic tanks as a cost containment strategy, was first in-flight drop tested in 2006 and achieved autonomous orbit in 2010. 


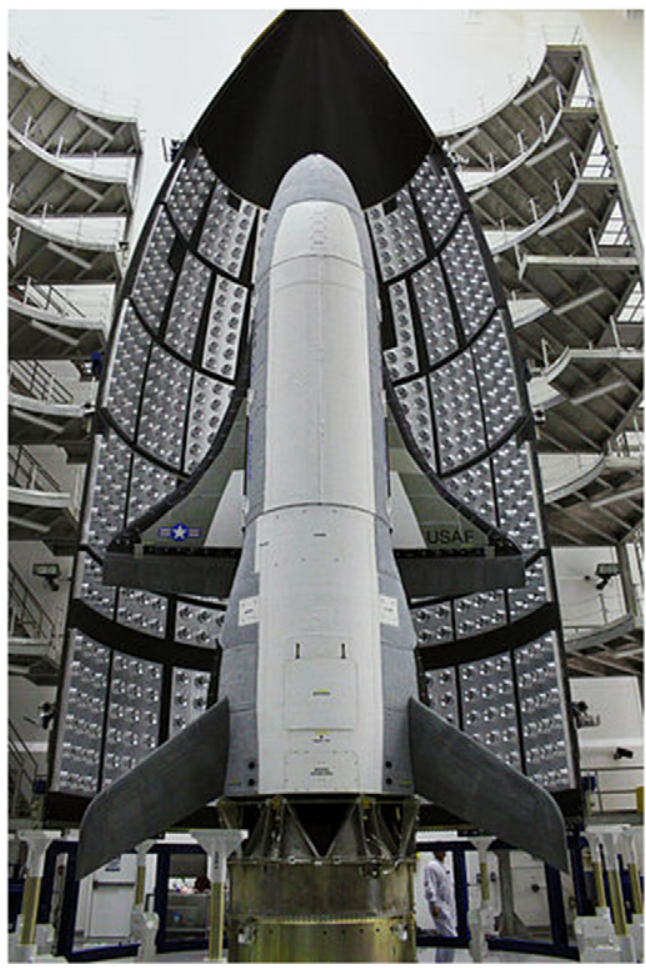

Fig. 8 Orbital space plane (OSP) X-37

As part of NGLT and OSP composite tank activities, Northrup Grumman (NG) was awarded a project directed toward building a subscale technology demonstration tank that was to incorporate improvements and lessons learned from X-33. The resultant 1.8 m diameter by $4.6 \mathrm{~m}$ long $1 / 4$ scale $\mathrm{LH}_{2}$ tank was built by NG and ATK at NASA MSFC. The NGLT tank used a permeation barrier and vented HC for in structure gas dissipation. Concurrently, NGLT and the National Center for Advanced Manufacturing (NCAM) funded research to help further understand the micro-cracking phenomenon at cryogenic temperatures $\left(-183^{\circ} \mathrm{C}\right.$ for $\mathrm{LOX}$ and $-253^{\circ} \mathrm{C}$ for $\left.\mathrm{LH}_{2}\right){ }^{13}$ Instead of trying to develop a composite material specifically designed for low temperature fuel containment, much of this research focused on commercially available composite materials. The efforts helped to confirm that, in lieu of a parasitic metal liner; micro-cracking could be reduced by using thin prepreg layers. ${ }^{14}$ The NG tank was fill-drain pressure cycled with $\mathrm{LH}_{2}$ more than 40 times. Also, in anticipation that industry autoclaves may not be large enough to process full-scale flight composite cryotanks, NG evaluated non-autoclave curing prepregs by building a two segment LOX/kerosene tank on the composite tank-set (CTS) program (Fig. 9).

As discussed in this section, composite cryotank evolution has been hampered by short development schedules, limited building block activities, tight budgets, cost overruns and program cancelations. Choosing to focus on near term permeation containment solutions (parasitic aluminum foil, thin ply uni-tape and vented sandwich materials), most programs did not undertake extensive new material evaluation activities. Pre-CCTD composite cryotank programs helped to show potential weight and performance benefits, but did not typically address flight vehicle level scale-up ( $>5.5 \mathrm{~m}$ ). Thus areas requiring additional industry-wide advancement included: infrastructure for $10 \mathrm{~m}$ scale (e.g., large autoclaves and AMP equipment) and cost competitive manufacturing processes versus aluminum (e.g., OoA materials, one-piece structural designs, and co-bonding instead of fastening to minimize parts).

\subsection{CCTD Program Overview}

Traditionally, government funded research programs have focused on advancing basic discipline or core level knowledge. Alternatively, the goal of NASA's Game Changing Development Program (GCDP) run CCTD effort was to mature technologies in preparation for system-level flight demonstrations by conducting large-scale laboratory experimentation and ground-based testing. ${ }^{3}$

The CCTD program leveraged past technology advancement programs and lessons learned from major system integrators, academic partners and governmental agencies. The two phased effort involved the design, manufacture, and test of large-scale composite cryotanks. Project scope included material selection, material allowables testing, manufacturing advancement, scale-up and full-scale component testing. ${ }^{15}$ Overall project goals were to provide $25-30 \%$ weight savings and a $20-25 \%$ cost savings over state-of-the-art aluminum-lithium (Al-Li) cryotanks.

For CCTD Phase 2, Boeing and NASA assembled an experienced team including; JI for tooling, Cytec Industries for OoA composite materials and Southern Research Institute (SRI) for permeation testing. Build activities were completed by Boeing at the ADC. Structural analysis was performed by both Boeing and NASA and environmental ground testing was conducted by NASA at MSFC. 


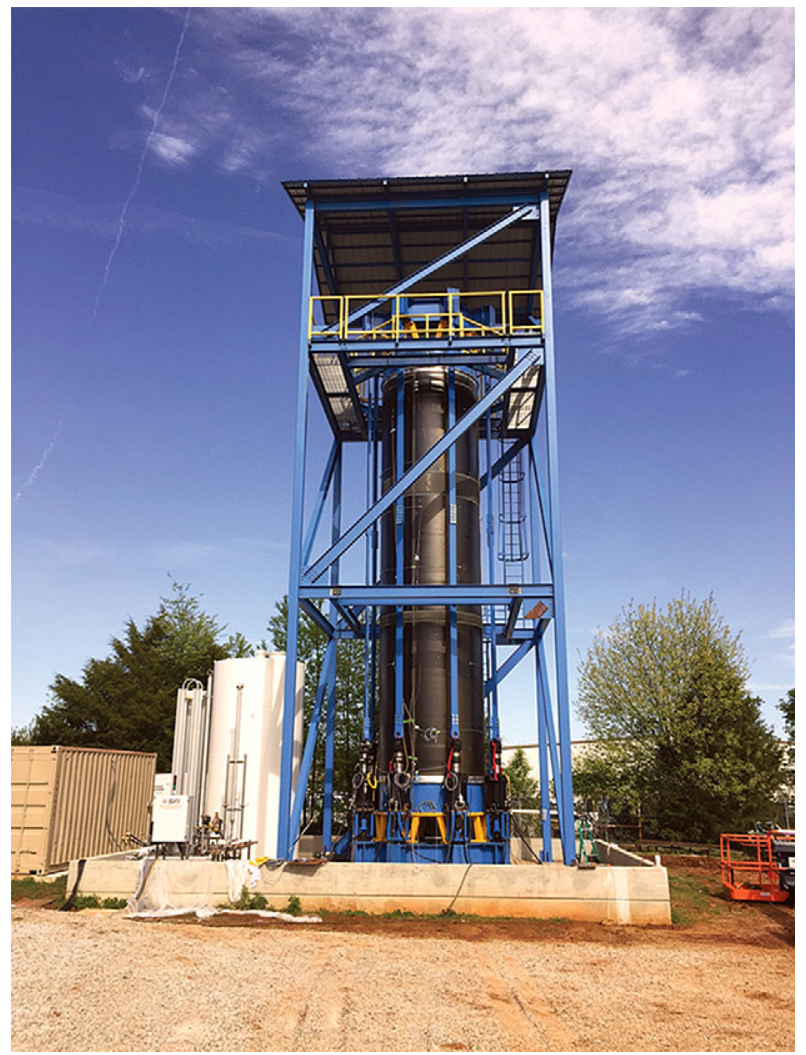

Fig. 9 NG two segment liquid oxygen (LOX)/kerosene tank.

On CCTD, NASA selected a $5.5 \mathrm{~m}$ test article to enable industry to produce and test the tank using existing infrastructure. A $5.5 \mathrm{~m}$ tank was deemed of sufficient scale to identify and reduce scale-up risks. For reference, NASA's SLS, currently planned for 1 st Launch in late 2018, has an $8.4 \mathrm{~m}$ upper stage $\mathrm{LH}_{2}$ tank and a $5.5 \mathrm{~m}$ LOX tank.

During Phase 1, NASA contracted with ATK, Boeing (it should be noted that Boeing and MDC merged in 1996), LM and Northrop Grumman for material equivalency testing, preliminary tank designs and manufacturing plans for a large-scale composite cryotank. Design requirements were for an early $10 \mathrm{~m}$ version of the SLS, rather than the current $8.4 \mathrm{~m}$ scale. Screening results indicated that three tested materials possessed the required strength for the application. Further, Boeing's design indicated that thin plies were effective at resisting micro-cracks and minimizing $\mathrm{LH}_{2}$ permeation. Boeing's analyses indicated that if the composite were worked to a moderately high strain level, 39\% weight savings compared to an Al-Li design could be realized. Further, their manufacturing cost analysis showed that a $20-25 \%$ cost saving could be achieved with a one-piece, RAFP'd, co-bonded design.

Designing for $8.4 \mathrm{~m}$ and building at $5.5 \mathrm{~m}$ ensured that the developed technologies encompassed the size envisioned for future heavy lift vehicles while fitting within existing infrastructures. A $5.5 \mathrm{~m}$ cryotank was deemed to be of sufficient scale (i.e., similar in size to existing EELV's) to help identify and reduce risks associated with scale-up (e.g., cost, schedule, manufacturing and inspection).

\section{Boeing's Tank Design and Manufacturing Approach}

The Boeing cryotank design (one-piece bellyband-less body with fluted core skirts) and manufacturing approach (RAFP material placement with hot/co-bonds to minimize fastening) was based on past development activities (including those of the merged MDC) and refined during internal trade study activities. As a precursor to CCTD, fluted core MRLs were advanced during the build of a $4 \mathrm{~m}$ dry structure barrel (Fig. 10). This large-scale test article was designed and built in support of NASA Langley's shell buckling knockdown factor (SBKF) program (Space Act Agreement SAA1-757). ${ }^{16}$ During CCTD Phase 1, Boeing refined its $5.5 \mathrm{~m}$ design to include the following features: (1) OoA prepreg, (2) thin uni-tape for low permeation combined with standard thickness uni-tape for rapid placement, (3) co-bonded skirts consisting of pre-cured quarter panel flutes with continuous inner and outer facesheets, and (4) y-joint softening strips to handle complex dome to skirt loading.

\subsection{Configuration Overview}

In a 29-month-period of performance; Boeing built two MDU's, a $2.4 \mathrm{~m}$ tank and a $5.5 \mathrm{~m}$ composite cryotank. Walls and joints of the tanks were designed to carry the line loads predicted for a $10 \mathrm{~m}$ tank. To allow for the option of curing in an oven, NASA chose 


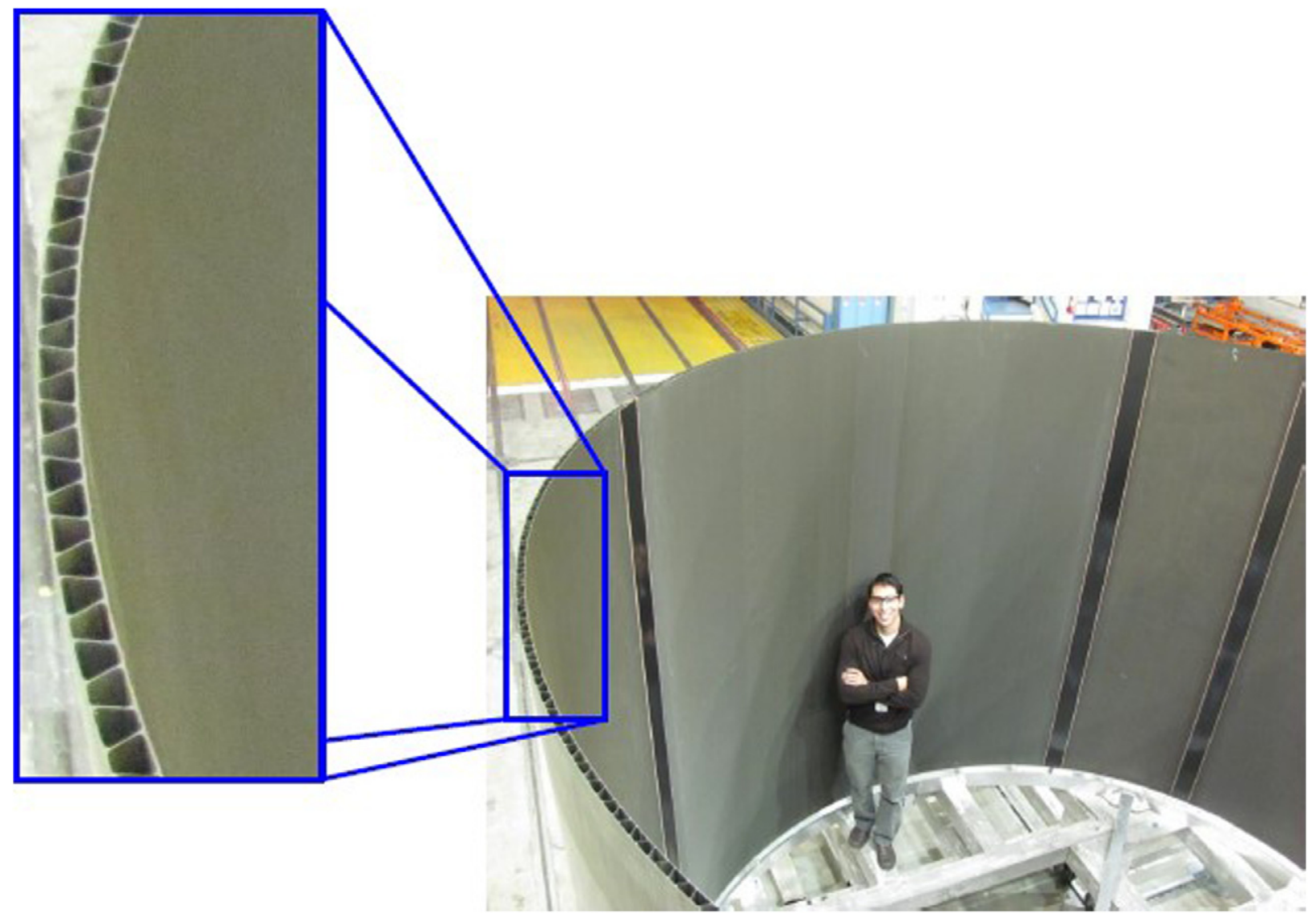

Fig. $104 \mathrm{~m}$ Dry structure shell buckling knockdown factor (SBKF) barrel.

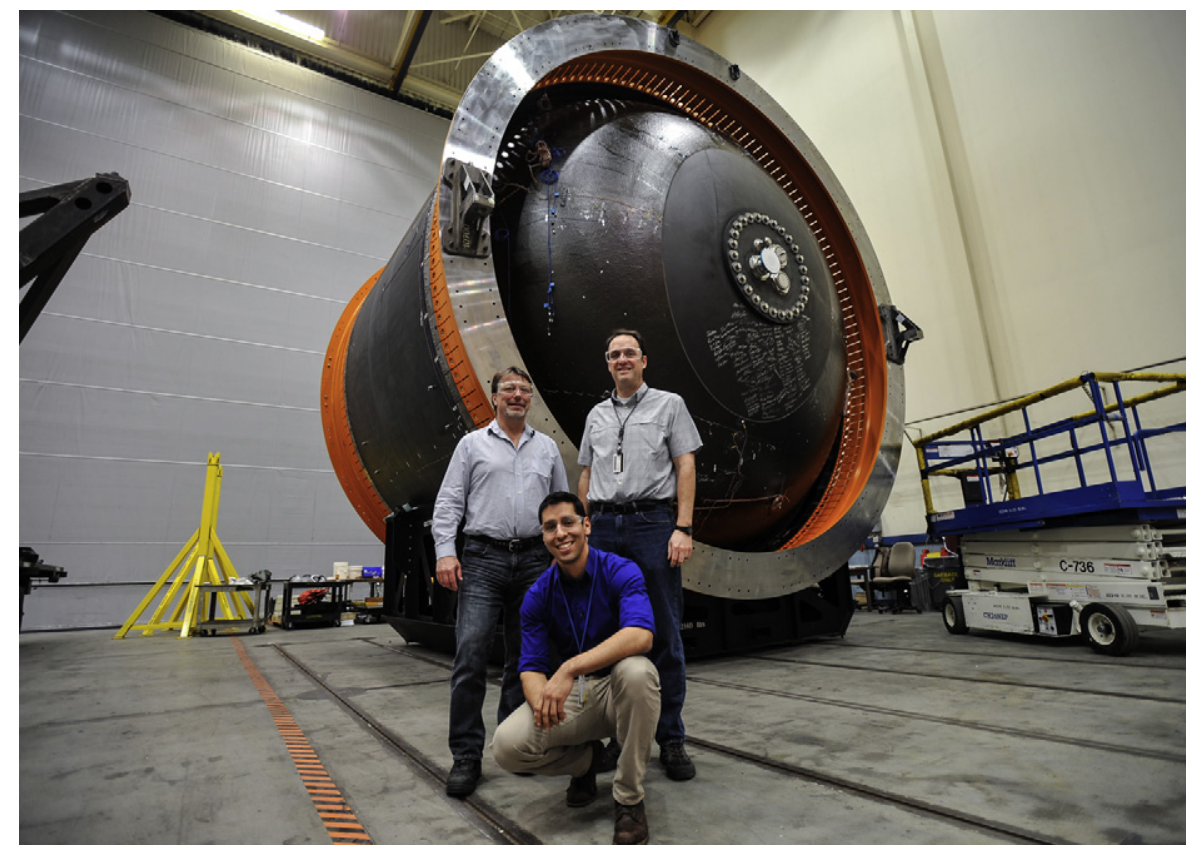

Fig. 11 Completed $5.5 \mathrm{~m}$ tank.

an out of autoclave resin system. ${ }^{17-19}$ Fig. 11 shows the completed $5.5 \mathrm{~m}$ tank. The tank shell was one-piece from dome-to-dome to minimize weight, reduce potential leak paths and maximize tank reliability. To meet out time considerations on the prepreg, the tank and dome covers were placed using right-sized RAFP equipment. Each dome had a scarf joint bonded cover to allow 


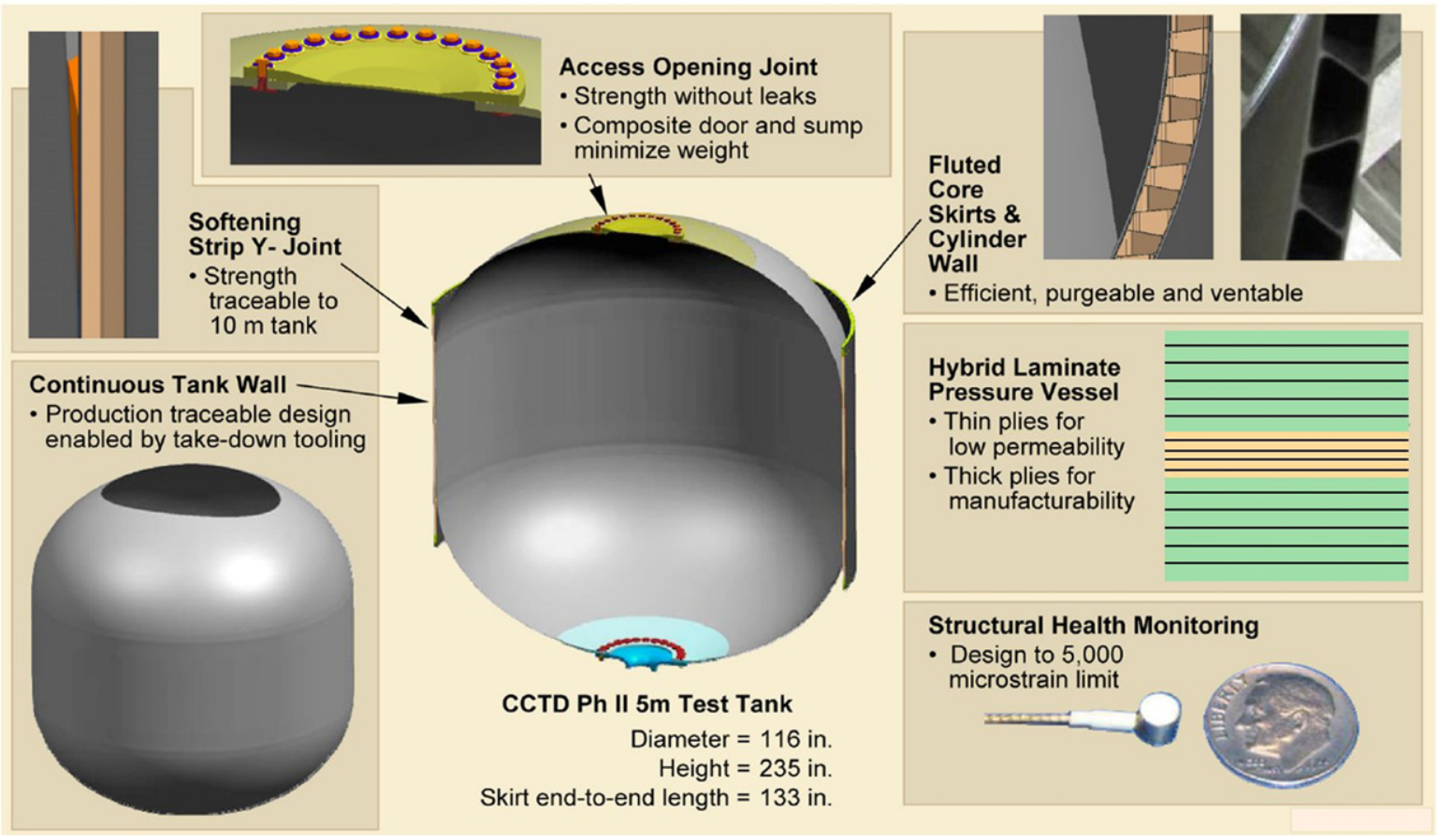

Fig. $125.5 \mathrm{~m}$ Tank design features.

for tool extraction. The domes contained bolted on access doors to enable manned access through $0.8 \mathrm{~m}$ diameter openings. The doors were hand laid up using plain weave fabric and contained cutouts for fill, drain, pressurization, venting, and instrumentation. Furon seals were used to make the door attachment leak-proof.

On the $5.5 \mathrm{~m}$ tank the cylindrical section of the tank was covered with fluted core sandwich skirts that extended beyond the dome's tangent area y-joint. The $2.4 \mathrm{~m}$ tank used a laminate skirt for ease of fixturing and cost containment (Fig. 12). Fluted-core consists of integral angled web members with structural radius fillers spaced between laminate face sheets. The fluted core skirts were designed to withstand launch vehicle primary loads and also to allow for purging and venting of what could otherwise be trapped gas. The skirt skins were co-bonded continuous construction so there were no adhesive bond lines that could degrade at cryogenic temperatures. Subscale fluted-core components created during the coupon and joint-testing phase of CCTD were shown to be stronger in shear and end-loaded compression, and were more damage-tolerant than conventional sandwich structure designs (e.g., $\mathrm{HC}$ and closed cell foam). ${ }^{17}$

Each end of the fluted core skirts were closed out with a series of metal fittings to accommodate handling, lifting and introduction of mechanical loads into the skirt during structural test. A 3-D softening strip was placed at the tank to skirt y-joint interfaces to maximize joint strength and reduce stress peaks. The tank walls contained a hybrid laminate stack of standard thickness grade 145 and thin uni-tape. The thin plies acted as a load sharing micro-crack resistant permeation barrier. Following tank shell initial cure, an acoustic health monitoring system was installed to record potential impacts during manufacture, transport, and test This type of real time sensing enabled tank design properties with low impact damage knockdowns to be considered during sizing.

\subsection{Materials}

For CCTD Phase 2, Boeing proposed a project scope of work, cost and schedule that could be executed using either autoclave or OoA material. On award, NASA chose to use carbon/epoxy OoA prepreg material. This material was chosen to allow future designs to consider oven cure. Having a design and manufacturing solution directly traceable to a $10 \mathrm{~m}$ cryotank was a major program objective and at the time the decision was made there were no autoclaves in the world large enough to cure a $10 \mathrm{~m}$ tank in one piece.

The bulk of the tank ( $80 \%$ by weight - tank shell, covers and skirt skins) was laid up using RAFP. The RAFP system demonstrated the ability to meet out-time constraints (typically around one month) using a combination thin and thick fully impregnated uni-tape. Conversely, the flutes and doors were made using hand laid dry core prepreg that wetted out during cure. This flow phenomenon allows for the removal of excess air in the layup and an out-of-autoclave curing epox, its ability to be cured in an oven using only vacuum pressure. The fully wetted prepreg had the ability to be cured OoA or in an autoclave using traditional $0.57 \mathrm{MPa}$ pressures.

The program used autoclave cures on small critical components (i.e., flutes, covers, and doors) that at a $10 \mathrm{~m}$ scale would fit in readily available autoclaves. Both prepreg versions can be stage-cured at either $93^{\circ} \mathrm{C}, 121^{\circ} \mathrm{C}$ and/or $177^{\circ} \mathrm{C}$; thus allowing for various partial cure (c-staging) options. ${ }^{19}$ When c-staging it is possible to remove tooling at lower than final cure temperature and conduct subsequent free standing post cures and/or bonds on the part. Careful selection of cure temperatures, pressure application 
and hold times produced acceptable final-part nondestructive inspection (NDI) quality (sufficient to meet the design allowables) on building block and final tank build activities. To validate design properties, a series of design allowables were created (e.g., base material, joint strength and permeation at cryo-temperatures temperatures under combined loads). Flute coupons were tested in compression and bending in hoop and axial directions at room and cryogenic temperatures.

\subsection{Tooling Approach}

The CCTD tank design specified a one-piece shell to minimize weight and reduce leak potential. To facilitate this design required internal multipiece fiber-placement breakdown mandrel capable of withstanding $177^{\circ} \mathrm{C}, 0.57 \mathrm{MPa}$ cures. Although Boeing was in production with $6 \mathrm{~m}$ diameter, 6 piece fuselage barrel tooling on the 787 program, on Phase 1 of the CCTD project, breakdown tooling of 16 pieces or more was identified as a risk area with low MRL. Tooling issues that needed development and demonstration to reduce this risk included: (1) scale-up, (2) extracting tool segments from small openings, (3) minimization of number of tooling segments and maintaining vacuum integrity through multiple cure and co-bond cycles. Boeing partnered with Janicki (JI) Industries (Sedro-Woolley, Washington) for the design and fabrication of these tools.

The $2.4 \mathrm{~m}$ tank provided an important learning opportunity for developing tool designs and fabrication methodologies that could be subsequently used on the $5.5 \mathrm{~m}$ tank. On the $2.4 \mathrm{~m}$ tank, the tool was broken into 24 sections with a split at the equator. The resultant large number tool seams made vacuum sealing challenging. For this one-off application disposable internal bags were used. The segments were solid laminate with each seam backed by a reinforcing strap (Fig. 13). ${ }^{15}$ The reinforcement/ stiffening straps provided features for bolting and pinning individual segments together. These laminates and straps, as well as the spindles, were analyzed using 3D finite element analysis (FEA) to ensure that all strength, deflection, and natural frequency requirements were met by the assembled tool.

After cure of the base tank, additional tooling was required to cure and co-bond the skirt to the cylindrical section of the tank. Each skirt alignment fixture (SAF) was an assembly of multiple segments that formed a cylinder on each end of the tank by mounting to the spindles (Fig. 14).

The tank tool, SAF and backing straps/segments were C/E laminates produced by vacuum-assisted resin transfer molding (VARTM). Because the tank was axially symmetric (axisymmetric), each hemispheric segment could be manufactured on one master tool. Upon completion of segment casting, the master molds were modified to become back-side trim and machine fixtures. The tool interfaces were machined to nominal dimension while loaded and indexed using a set of coordination features. The surfaces that mated with the backing straps were machined to a known thickness, fastener holes were placed, and the segment edges were trimmed during a single numerically controlled (NC) machining setup. The mating surfaces of the backing straps were match-machined to ensure fit-up during assembly of the tank and SAF tools.

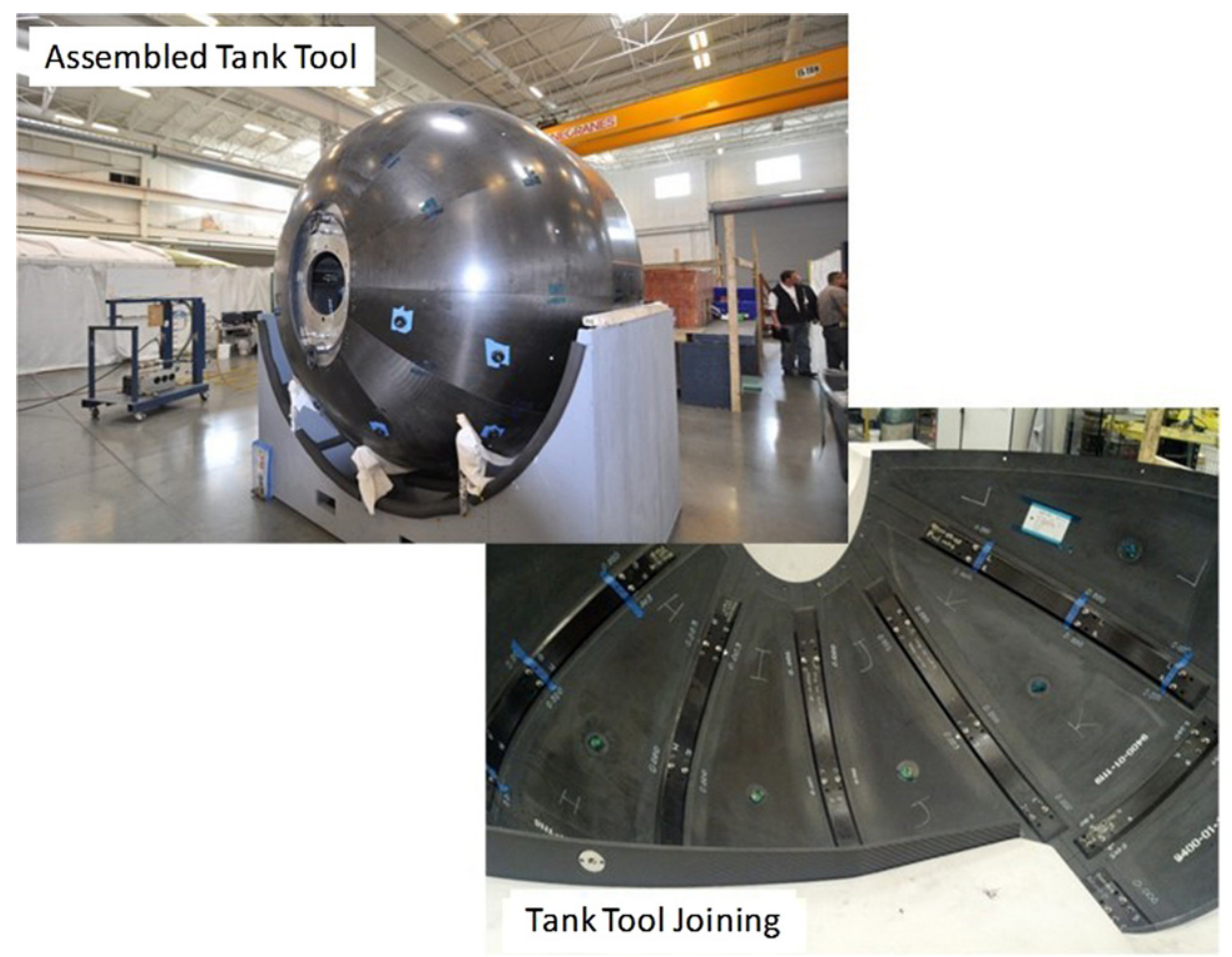

Fig. 132.4 m Tank layup mandrel. 


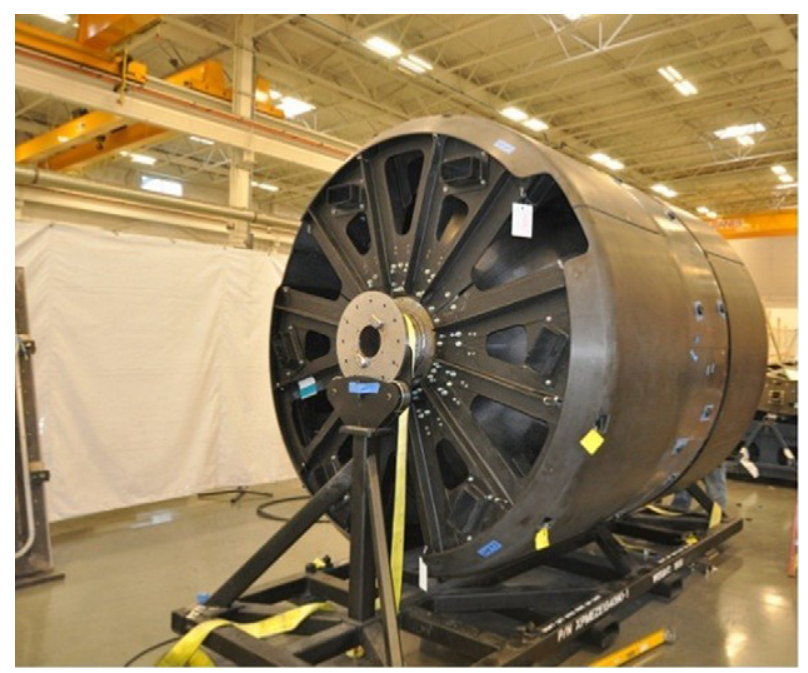

Fig. 142.4 m Skirt alignment fixture (SAF).

The tank tool assembly joined in high-tolerance assembly jig. Segments were pinned into location using bushings placed in the jig's surface and held in place with vacuum, which set the outside mold line (OML) contour of the tool. Backing straps were then placed, match-drilled, and pinned in place. After the first tank tool half was assembled, it was removed and the process repeated. Finally, the first half of the tank was inverted and fastened to the second half.

In addition to the tank cure/layup mandrels, manufacture of the tanks required numerous piece part layup tools (i.e., flutes, caps, covers, and doors), support stands, lifting/rotating fixtures, transportation carts, tool extraction aides and overhead moving equipment (OHME) (Fig. 15).

\subsection{Manufacturing Approach}

CCTD manufacturing activities were aimed at scaling up Boeing's highly automated fabrication approach and in so doing increase composite cryotank TRL and MRL from to the 5-6 range (i.e., show the capability to model, design, manufacture and test subscale prototype hardware in a production environment). Beyond building a high quality testable article, a primary goal was to demonstrate the potential to reduce recurring cost versus a metallic tank by $25 \%$. To achieve this goal, Boeing created a manufacturing flow containing the following processes: (1) RAFP of approximately $80 \%$ of the structure, (2) multipiece breakdown tooling that allowed for the creation of a one-piece tank, and (3) structurally efficient co-bonded and hot bonded joints with fluted core skirts.

\section{Tank Development and Build Activities}

In order to achieve a 5-6 TRL/MRL a component must be made using mature processes and tooling in a production facility. To demonstrate this on CCTD, the MDU's and tanks were built at the Boeing ADC in Seattle, Washington (Fig. 16). This facility has manufactured numerous large structural composite products (e.g., B-2 wings, Sea Launch fairings, and 787 fuselage barrels). It has built-in material handling and quality control systems, including; trim, overhead moving, clean rooms, optical laser templates (OLT), AMP systems, ovens/autoclaves and automated ultrasonic scanning systems (AUSS). To complement existing capabilities, Boeing upgraded (new drive and rails) a laboratory robotic placement system (used on the MDUs and $2.4 \mathrm{~m}$ tank) and purchased a new robot for $5.5 \mathrm{~m}$ tank build.

\subsection{Process Development, Building Block Activities}

CCTD building block activities were aimed at increasing TRL/MRL and providing lessons learned prior to $5.5 \mathrm{~m}$ tank build. As shown in Fig. 17, steps included: material selection, coupon/joint testing, MDU trials and 2.4/5.5 m tank build.

The MDUs were fabricated to address flute scale-up and y-joint interface issues. These components were dimensional and ultrasonically inspected, but not destructively, tested (Fig. 18).

MDU1 was a $0.5 \mathrm{~m} \times 3.0 \mathrm{~m}$ curved fluted core panel with continuous skins and a flute center joint. This component was made to demonstrate flute-to-flute and flutes to fiber placed inner and outer skin bonding. After cure, MDU1 was inspected to check joint and skin-to-flute bond integrity using the AUSS. The tooling and manufacturing items addressed by MDU1 included: (1) flute mandrel scale-up, (2) flute joint fit-up and design, (3) cure temperatures and pressures, (4) flute wrapping scale-up, and (5) flute 

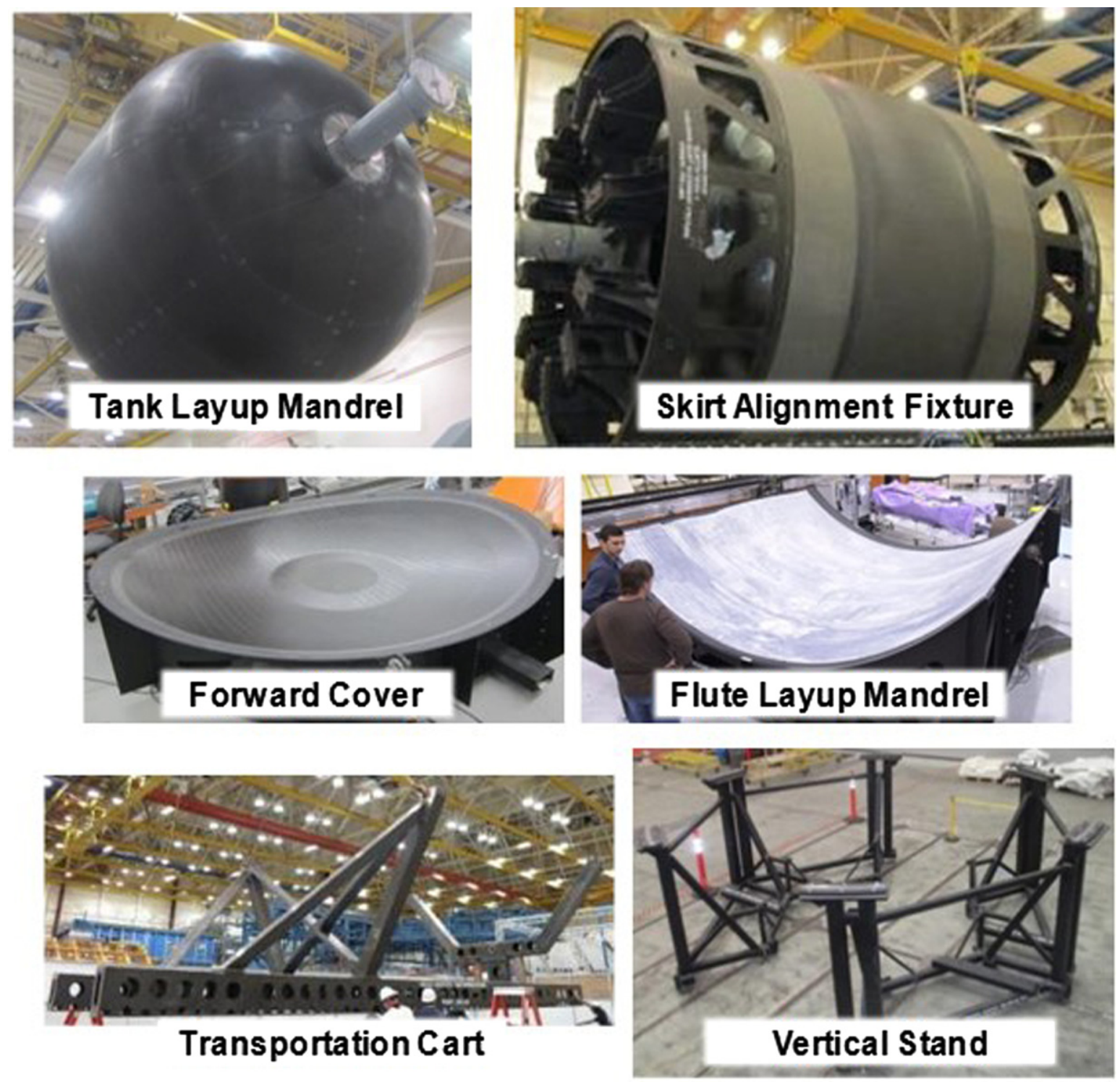

Fig. 15 Composite cryotank tooling package.

pack stacking. MDU1 helped to mature flute height and length capabilities. Also, optimizations were accomplished on flute wrapping, noodle build/insertion, and flute mandrel tooling. Lessons learned were applied to flute panel build and co-bond on the $5.5 \mathrm{~m}$ tank.

MDU2 was 1.0 by $1.0 \mathrm{~m}$ and consisted of a jointed fluted core co-bonded to a tank shell and skirt skin. Initially, the tank shell was cured with a y-joint softening strip. As with both the 2.4 and $5.5 \mathrm{~m}$ tanks, STT was used for RAFP of the tank and skirt skins. Because of the high number of tows required to make a course and lap/gap allowances, the surfaces of these skins were rougher and more challenging to fit-up than typical hand-placed tape skins. A SAF tool segment was fitted to the tank segment tool prior to fiber placing the skirt inner skin. Two flute segments were assembled onto the inner skin and then the outer skin was fiber placed. After the skirt was co-bonded, a pre-cured purge barrier was bonded into the cavity between the softening strip and skirt. Finally, the component was trimmed to final dimensions. The tooling and manufacturing items addressed by MDU2 included: (1) softening strip fabrication/joining to tank shell, (2) fit-up of the fluted core skirt, and (3) NDI of individual pieces and completed assembly.

\section{$4.2 \quad 2.4$ m Precursor}

As part of CCTD building-block risk reduction activities (and in parallel with MDU's), Boeing fabricated a $2.4 \mathrm{~m}$ precursor cryotank. The $2.4 \mathrm{~m}$ fabrication and instrumentation activities were focused on increasing composite cryotank MRL while reducing risks associated with building a $5.5 \mathrm{~m}$ tank. Before component fabrication activities, detailed manufacturing and inspection plans 


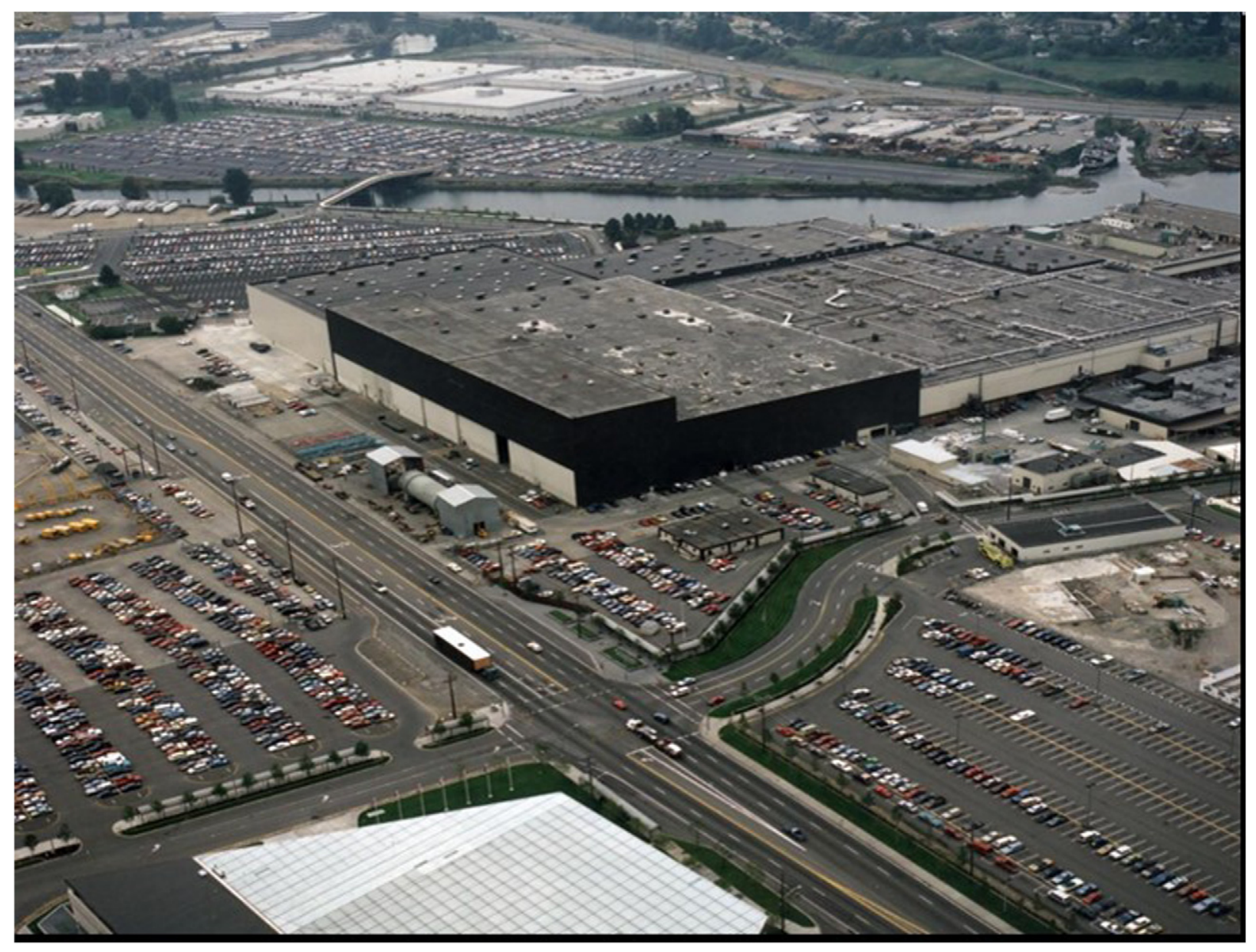

Fig. 16 Boeing's Advanced Development Center (ADC).

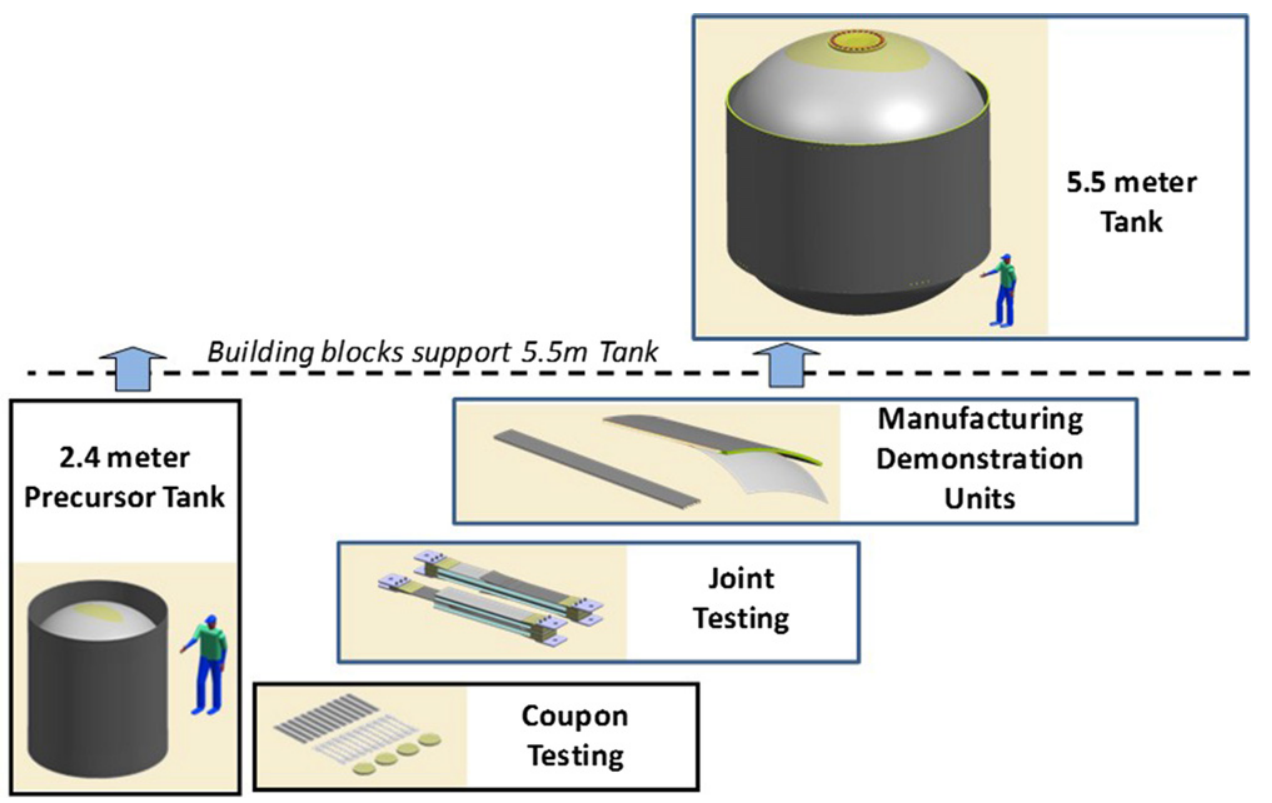

Fig. 17 Composite cryotank technology development (CCTD) building block activities. 

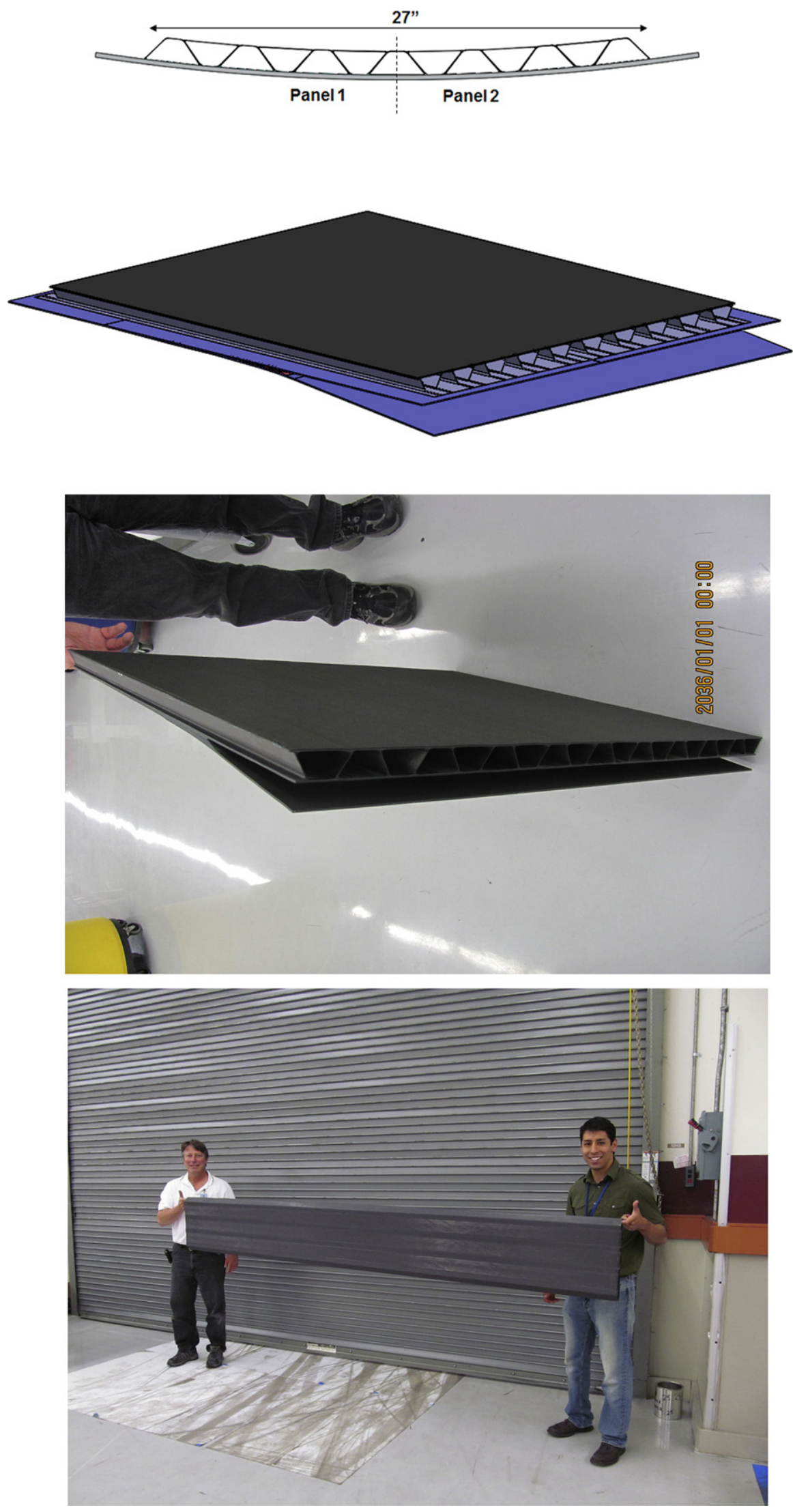

Fig. 18 Manufacturing demonstration units (MDUs). 
(containing such items as material specifications, manufacturing drawings, build guides, process tip/limit sheets, and inspection points/criteria), were generated. The $2.4 \mathrm{~m}$ tank encompassed several challenging design features: (1) one-piece co-cured/cobonded spherical geometry with integral skirts, (2) OoA curing materials, (3) permeation-resistant thin/hybrid ply laminate skins, and (4) off-angle STT construction. Lessons learned were compiled and used to help guide $5.5 \mathrm{~m}$ build activities.

The one-piece tank design required that the layup mandrel be broken into small segments that could be removed through a forward elliptical opening. To achieve a good vacuum during cure, inner and outer bags were used. SAF were used to join the skirt to the tank. A list of the tooling used to build the $2.4 \mathrm{~m}$ tank is provided below:

1. Tank layup mandrel - 24 piece liquid molded C/E.

2. SAF that interfaced with tank tool to allow for skirt layup (also C/E construction).

3. Ancillary C/E cure tools (sump cap, forward cover, sump and forward door).

4. Ancillary lifting fixtures and stands (aluminum and steel).

Fig. 19 summarizes the manufacturing flow used to build the $2.4 \mathrm{~m}$ tank. Fabrication of this tank provided the opportunity to work through all key processes (excluding flutes) needed to fabricate the $5.5 \mathrm{~m}$ tank. The manufacturing flow contains the following key steps: (1) layup/pre-cure/NDI sump cap, forward cover, and purge barriers, (2) AFP/cure/NDI inner tank shell, (3) AFP skirt/co-bond/NDI, (4) de-tool, (5) instrumentation, (6) cover and door assembly, and (7) leak test/insulate/package.

Approximately $80 \%$ of the tank, by weight, was placed using a RAFP system. The $2.4 \mathrm{~m}$ robotic AFP cell had to be able to accomplish the following: (1) reach the dome ends, (2) lay thin prepreg, and (3) have a head small enough to lay-up material close to the cure mandrel shaft. To meet these requirements, Boeing designed and assembled a customized laboratory-scale RAFP system.

The RAFP system required preprogramming of the individual thin and thick tape courses. Highly contoured dome ends with tight spiral orientations required the use of $0.32 \mathrm{~cm}$ STT, whereas the constant diameter skirt could be completed using $0.64 \mathrm{~cm}$ tape and a wider bandwidth. Pound-per-hour rates and observed learning curves were recorded for each component. Later these values were compensated for bandwidth and course length to estimate $5.5 \mathrm{~m}$ tank layup times. The tank and subcomponents (i.e., forward dome and sump cap) were laid up within the material's out-time using a single-headed RAFP.

The covers, doors and barriers were placed on separate LMs and subsequently bonded or fastened onto the tank (Fig. 20). The tank and skirt was laminated in a horizontal configuration and then the tank was rotated vertical for tool extraction and final assembly. The $2.4 \mathrm{~m}$ tank used a thick laminate skirt instead of the fluted core design used on the $5.5 \mathrm{~m}$ tank. Placement of the skirt skin required the addition of SAF tooling segments (Fig. 21).

The $2.4 \mathrm{~m}$ tank incorporated numerous bonds to eliminate fasteners, minimize manufacturing cost, maximize strength and reduce potential leak paths. The quality of the bond preparation was checked per specification prior to applying film or paste adhesive depending on the location and strength requirements. Cure and bond cycles were chosen to maximize handling ability and minimize the amount of high-temperature cures that any given component would be subjected to. Components that were small enough at a $10 \mathrm{~m}$ scale to fit in current-generation autoclaves were cured at full pressure and vacuum. Components that would require an autoclave larger than what currently exists in the industry at a $10 \mathrm{~m}$ scale (tank body and skirt) were cured in a

PROGRAM PLY PATHS
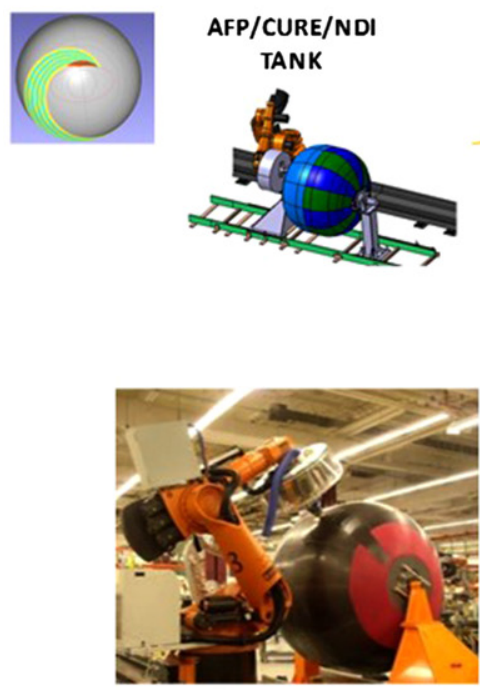

Robotic Fiber Placement

\section{INSTALL HEALTH MONITORING}

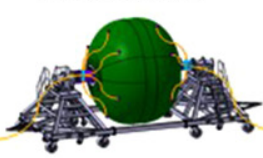

BOND/NDI SOFTENING STRIPS

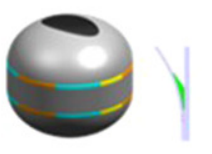

AFP/CURE/NDI SKIRT SKIN
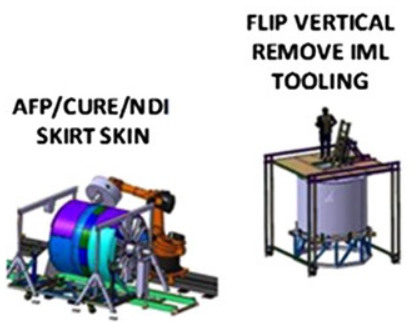

FNAL ASSY INSULATE LEAK CHECK

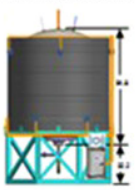

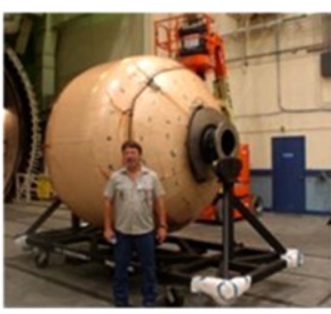

Break down tooling \& Cures

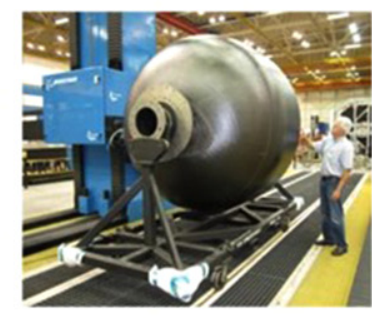

NDImethods

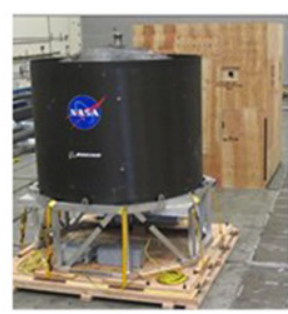

Shipping

Fig. $192.4 \mathrm{~m}$ Cryotank manufacturing flow. 


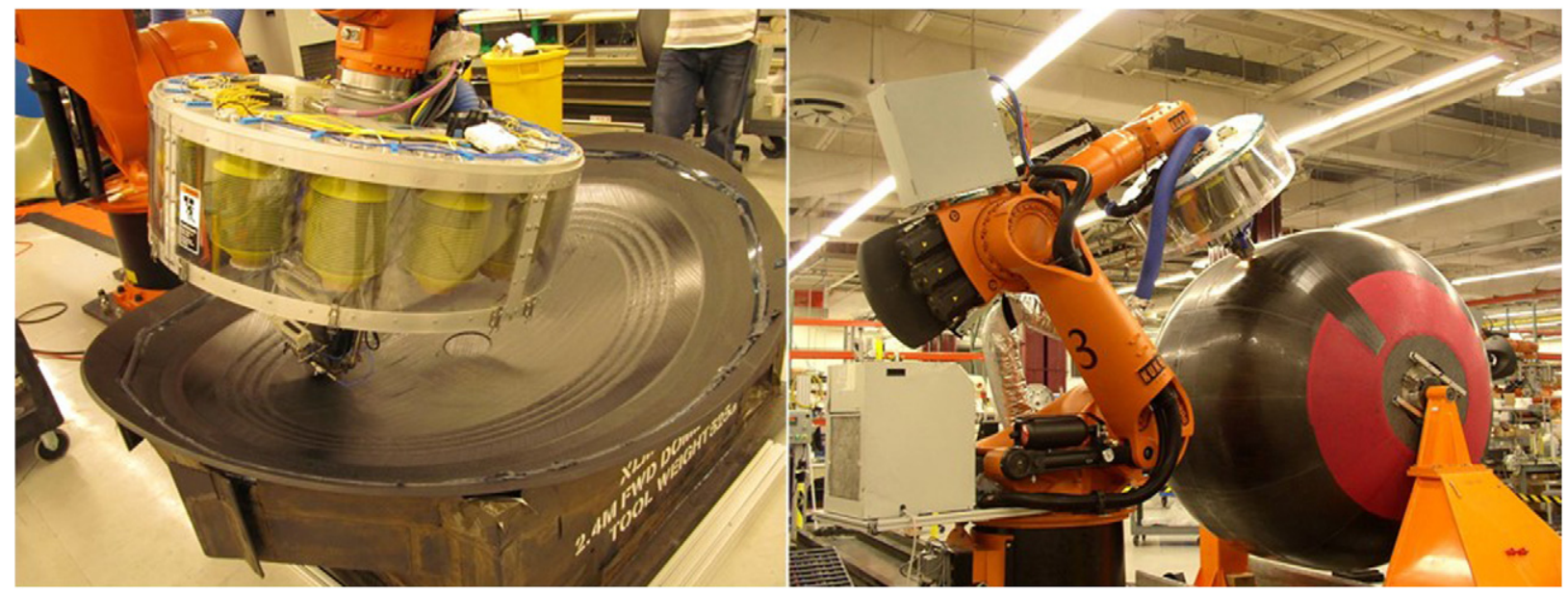

Fig. 20 Forward cover and tank skin placement.

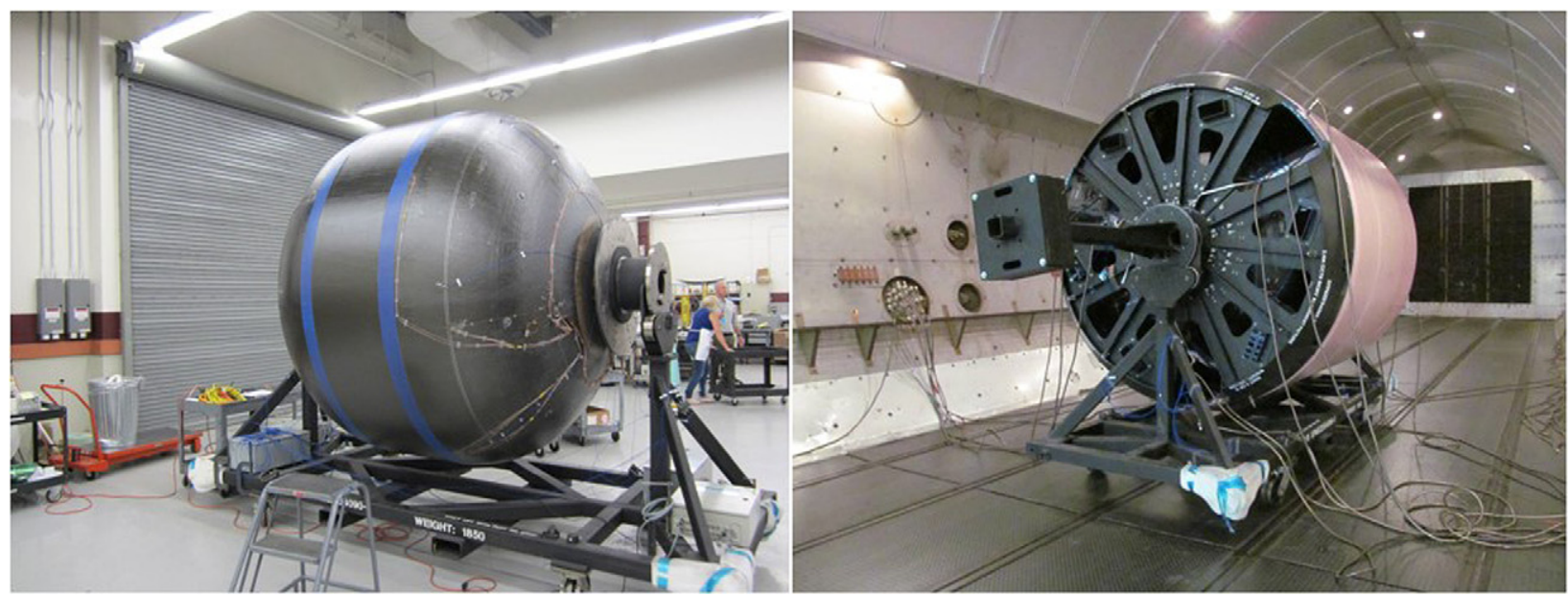

Fig. 21 Tank shell after initial cure and skirts ready to co-bond.

low-pressure oven environment. Through-transmission ultrasonic (TTU) and/or pulse-echo (PE) NDI were performed following each cure and/or bond (Fig. 22). Final assembly of the $2.4 \mathrm{~m}$ tank involved fastening the sump, bonding on a permeation measurement bag, and bolting the skirt to a vertical stand. Subsequently, the tank was pressure tested with helium.

As part of the overall quality control system, an acoustic emission (AE) SHMS was installed after initial tank shell cure. This system was designed to detect and triangulate low level impacts during manufacture, transport and test; and therein allowing the tank design to consider expected defect levels/sizes. The tank was fitted with internal and external strain gages for use during final test.

After final assembly, the tank was shipped overland on a vertical stand from Seattle to Huntsville (NASA MSFC) (Fig. 23). At Marshall the tank received spray on foam thermal protection and was pressure tested at cryo-temperatures. The successful test, combined with lessons learned during manufacture, served to advance composite cryotank TRL and MRL.

\section{$4.3 \quad 5.5 \mathrm{~m}$ Full-Scale Tank}

Fabrication of the $5.5 \mathrm{~m}$ tank was the culmination of CCTD manufacturing efforts. With a CCTD program primary goal to raise TRL/MRL to the 5-6 range, the effort incorporated lessons learned during MDU and $2.4 \mathrm{~m}$ build activities. The tank was built full thickness for a $10 \mathrm{~m}$ design and therein addressed most of the high risk manufacturing issues (e.g., multipiece breakdown tooling, prepreg material out time, large-scale complex geometry RAFP, low pressure cure cycles, in-plant moving/ flipping and staged cure/bond cycles).

Listed below and shown in Fig. 24 are the manufacturing steps used to build the $5.5 \mathrm{~m}$ tank:

1. RAFP or hand layup and cure subcomponents: sump cap, forward cover, sump and forward door in an autoclave.

2. RAFP and cure tank shell. 


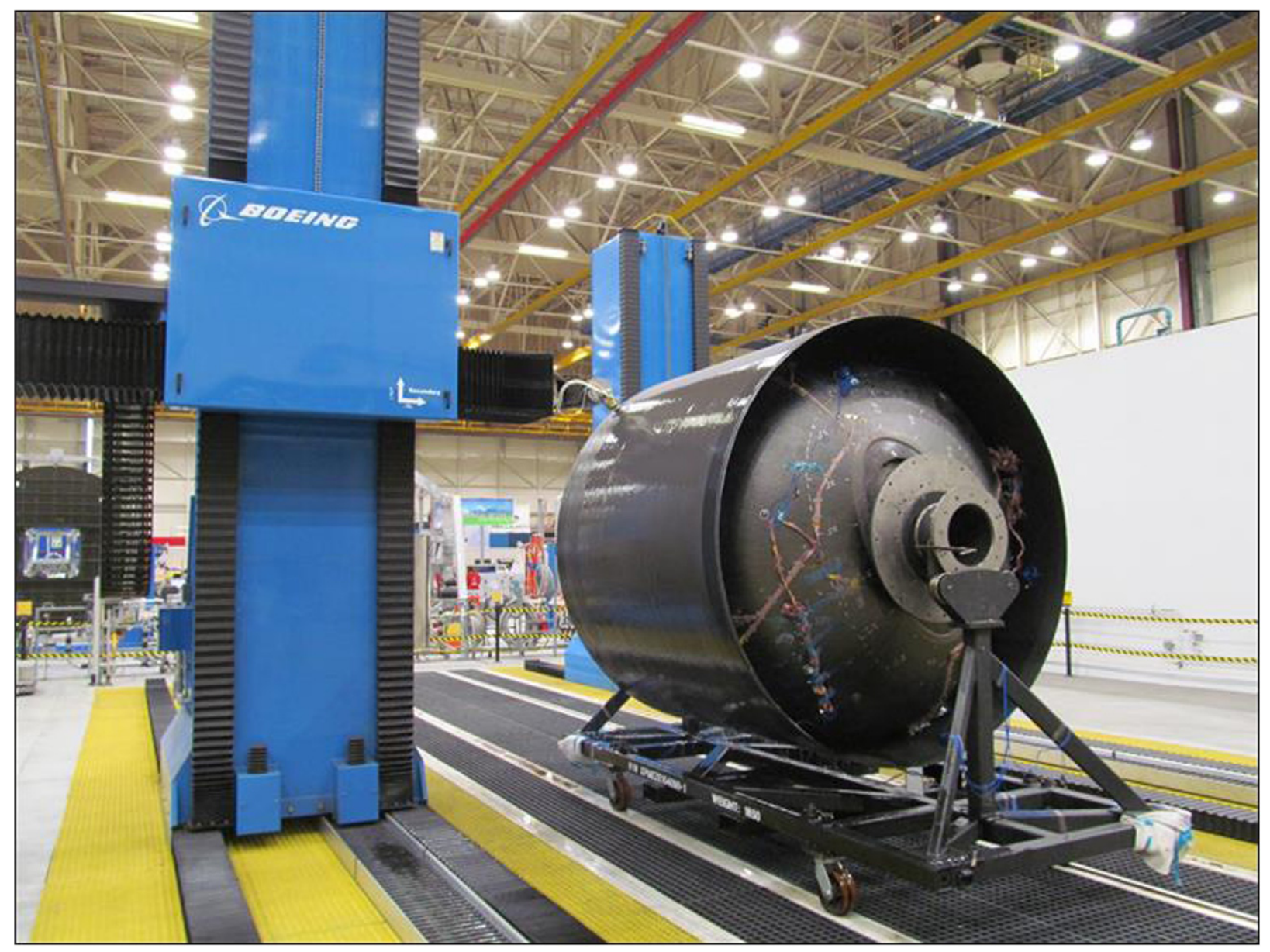

Fig. 22 Through-transmission ultrasonic (TTU) of $2.4 \mathrm{~m}$ skirt.

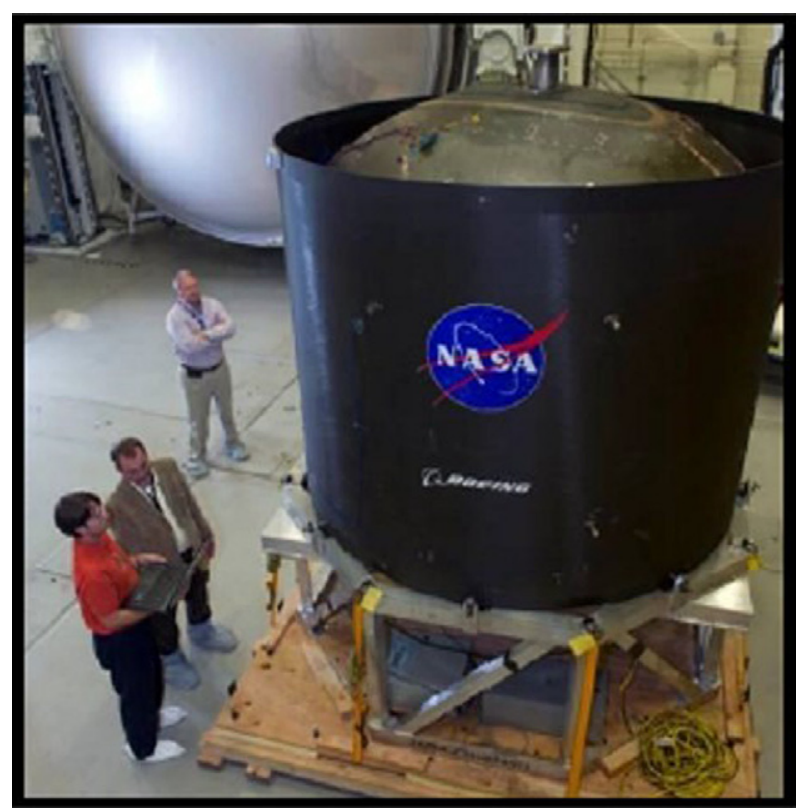

Fig. $232.4 \mathrm{~m}$ Tank delivery to George C. Marshall Space Flight Center (MSFC). 

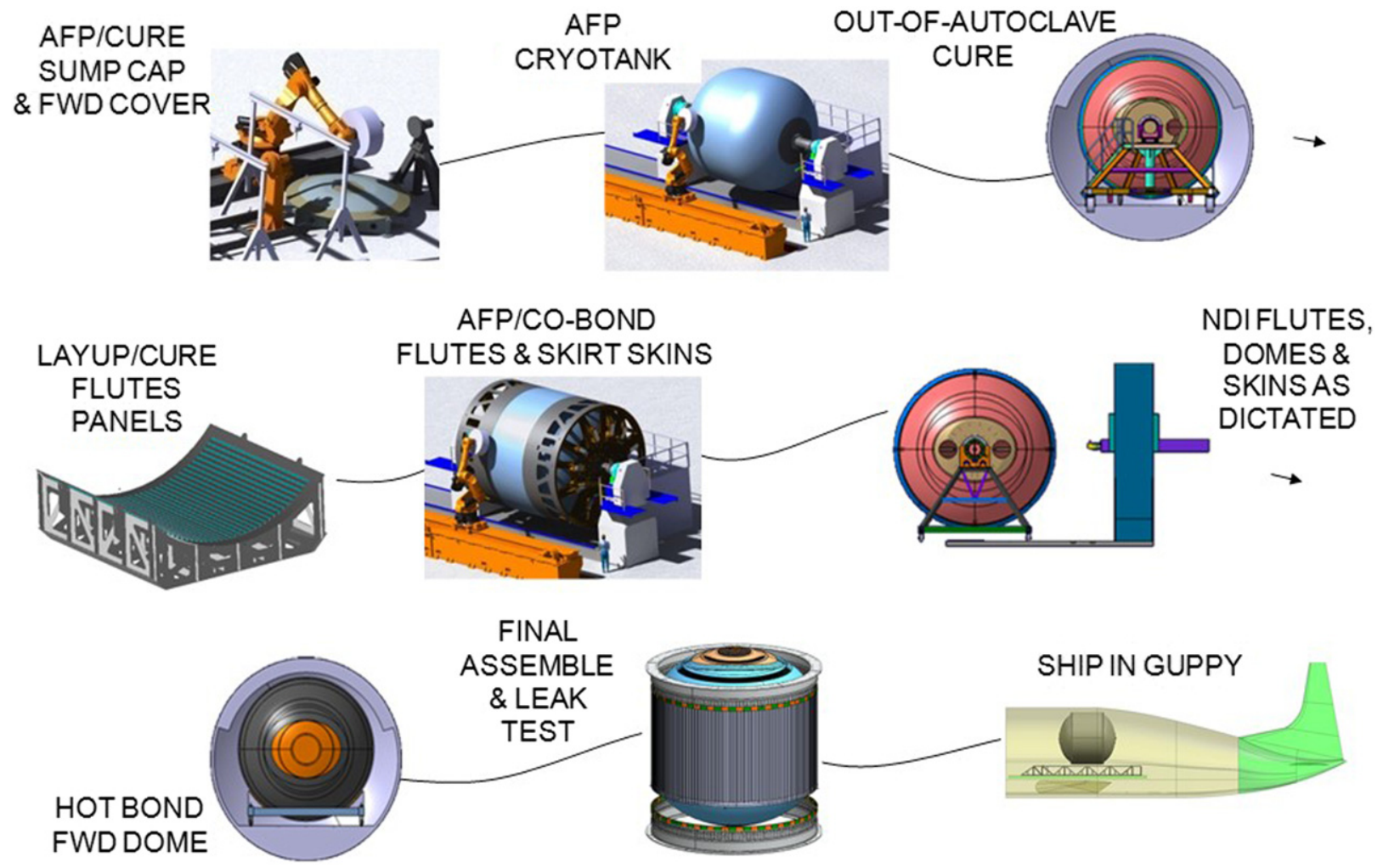

Fig. $245.5 \mathrm{~m}$ Manufacturing flow.
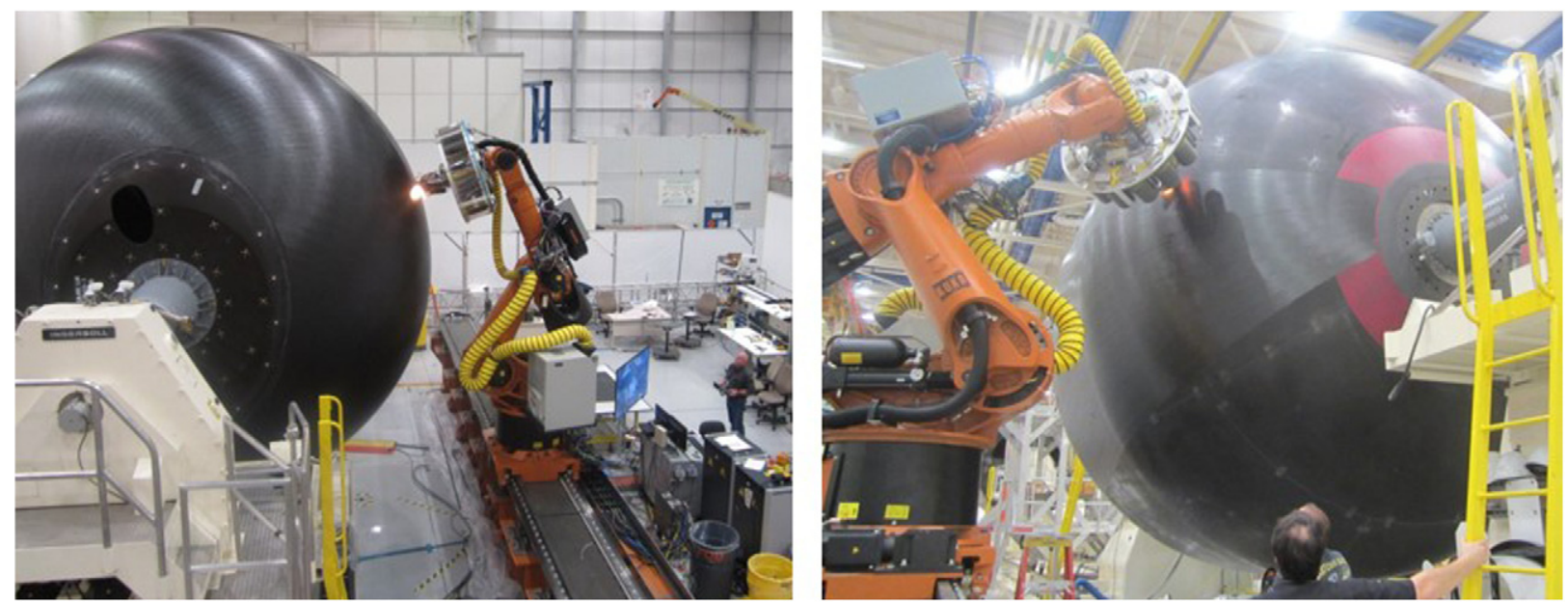

Fig. $255.5 \mathrm{~m}$ Robotic automated fiber placement (RAFP).

3. Layup and cure flute quarter panels.

4. Install softening strip, SAF, RAFP skirt skins, install flute panels and OoA co-bond.

5. NDI flutes, domes, covers, tank and skins as required after every cure.

6. Assemble end fittings, finger rings, doors and leak test.

7. Ship to MSFC on Super Guppy.

As shown in Fig. 25, for the $5.5 \mathrm{~m}$ tank Boeing developed a customized RAFP system. The system was based on Boeing patents and had a head that used $0.64 \mathrm{~cm}$ STT. The head and tail stock were developed by Kuka Robotics. NC programming was accomplished using CGTech's VERICUT composite programming (VCP) software. Lay down accuracy met Engineering requirements without additional accuracy augmentation. Layup quality (laps and gaps) was as good as what is typically achieved with traditional computer numerical controlled (CNC) AFP machines. 
The robotic system provided several advantages over a traditional fiber placement machine, such as: (1) agile and affordable integration of a head specifically designed to meet CCTD requirements, (2) on board payload capacity that insured clean fiber paths and reduced the amount of tow twists and folds, and (3) reach sufficient across the entire tank to hit all dome ends and cylindrical sections. Laydown rates were sufficient to meet project out-time requirements (typically 30 days). The steeper the fiber angle (as is the case on the dome ends), the greater the amount of steering that was required to maintain fiber angularity. Previously considered only for small-scale applications, the robotic RAFP demonstrated the viability of using such platforms on large scale components.

The forward cover and sump cap were placed using a laboratory RAFP and, as with the flutes, were co-bonded to the tank shell. The skirt skins were continuous and placed directly onto the tank shell with the aid of the SAF. A 16-piece internal layup mandrel, which could be extracted through the forward dome opening, was used to create the body of the tank, and SAF tool extensions were used to join the fluted core sandwich skirt to the tank.

The individual components that constituted the tank were cured using multiple staged-step temperature holds and pressures in line with current industry capabilities. Components that were small enough at a $10 \mathrm{~m}$ scale to fit in current-generation autoclaves were cured at $0.57 \mathrm{MPa}$ with $94.8 \mathrm{kPa}$ vacuum. Components that required an autoclave larger than that which currently exists in the industry at a $10 \mathrm{~m}$ scale (tank body and skirt skins) were cured in a low-pressure oven environment.

As with the $2.4 \mathrm{~m}$ tank, the $5.5 \mathrm{~m}$ tank incorporated numerous bonds to eliminate fasteners, minimize manufacturing cost, reduce leak path potentials and optimize strength. Cure and bond cycles were chosen to maximize handling capability and minimize the amount of high-temperature cures that any given component would be subjected to. The quality of the bond surface preparation (differing combinations of standard industry hand sand, peel ply or bead abrasion) was checked against specifications prior to bond. Film adhesive was used on all structural bonds and paste was used on noncritical applications. NDI via TTU, PE and flash thermography was performed following each cure and/or bond.

Following tank shell placement, cure, and inspection, quarter barrel fluted core panels (approximately 3.7 by $4.9 \mathrm{~m}$ ) were placed around the tank and wrapped with continuous inner and outer skins. For comparison, HC panels are typically $0.9 \mathrm{~m}$ by $1.5 \mathrm{~m}$ and require foaming adhesive or potting compound shear joints. Fluted core is an alternative to $\mathrm{HC}$ and has good weight to bending stiffness capabilities when subjected to axial compression loads. Since fluted core replaces HC and adhesive layers with co-cured integral angled web members and structural radius fillers, it can be lower weight on large structures. To support flute scale-up, Boeing conducted a series of building block activities: element component, MDU and $4 \mathrm{~m}$ dry structure barrel for the NASA SBKF program.

Flutes were made from C/E prepreg tape, stacked together onto a cure mandrel and radius fillers were inserted at all web-to-cap interfaces (Fig. 26). After cure, the flute panels were fit to each other and continuous green inner and outer facesheets were fiber-placed and co-bonded onto the tank to complete the skirts.

The tank tool remained in place from initial fiber placement of the tank through skirt co-bond. Subsequently, the SAF was removed in the horizontal position and the tank was flipped vertical for tank tool extraction. In the vertical configuration, the center spindle and forward dome tools were removed; allowing man entry to the inside of the tool. The tooling segments were removed in sequential order from forward, mid, to aft using specially designed lifting fixtures (Fig. 27).

Individual subcomponents (i.e., domes and covers) were inspected using traditional water-based TTU, the tank and skirt acreage and bond areas required the use of single sided PE phased array end effectors (Fig. 28). Inspection was conducted after every cure cycle to insure that required laminate quality was achieved prior to advancing to the next placement or bonding operation. Initial interrogation of the tank shell was accomplished prior to cure tool extraction. Final assembly included installation of the forward door, sump, end fittings, finger-rings, and permeation bags. The door and sump were installed with
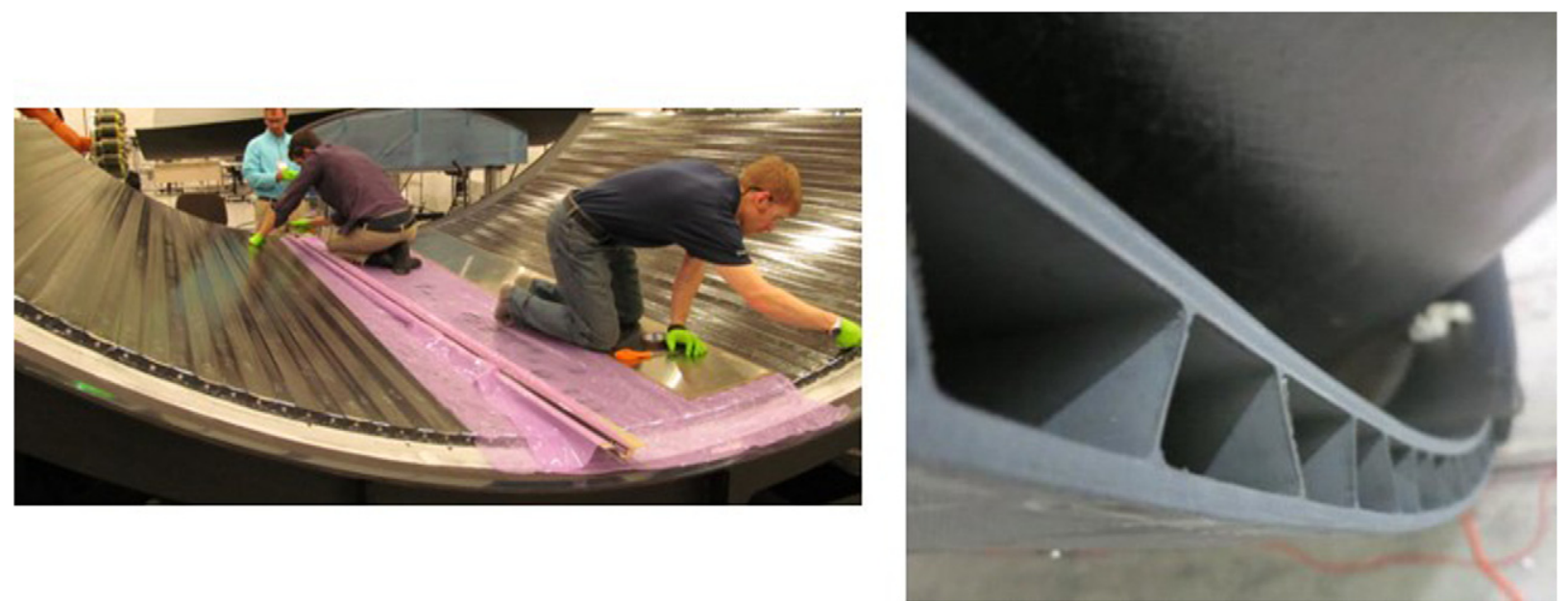

Fig. 26 Fluted skirt manufacturing flow. 

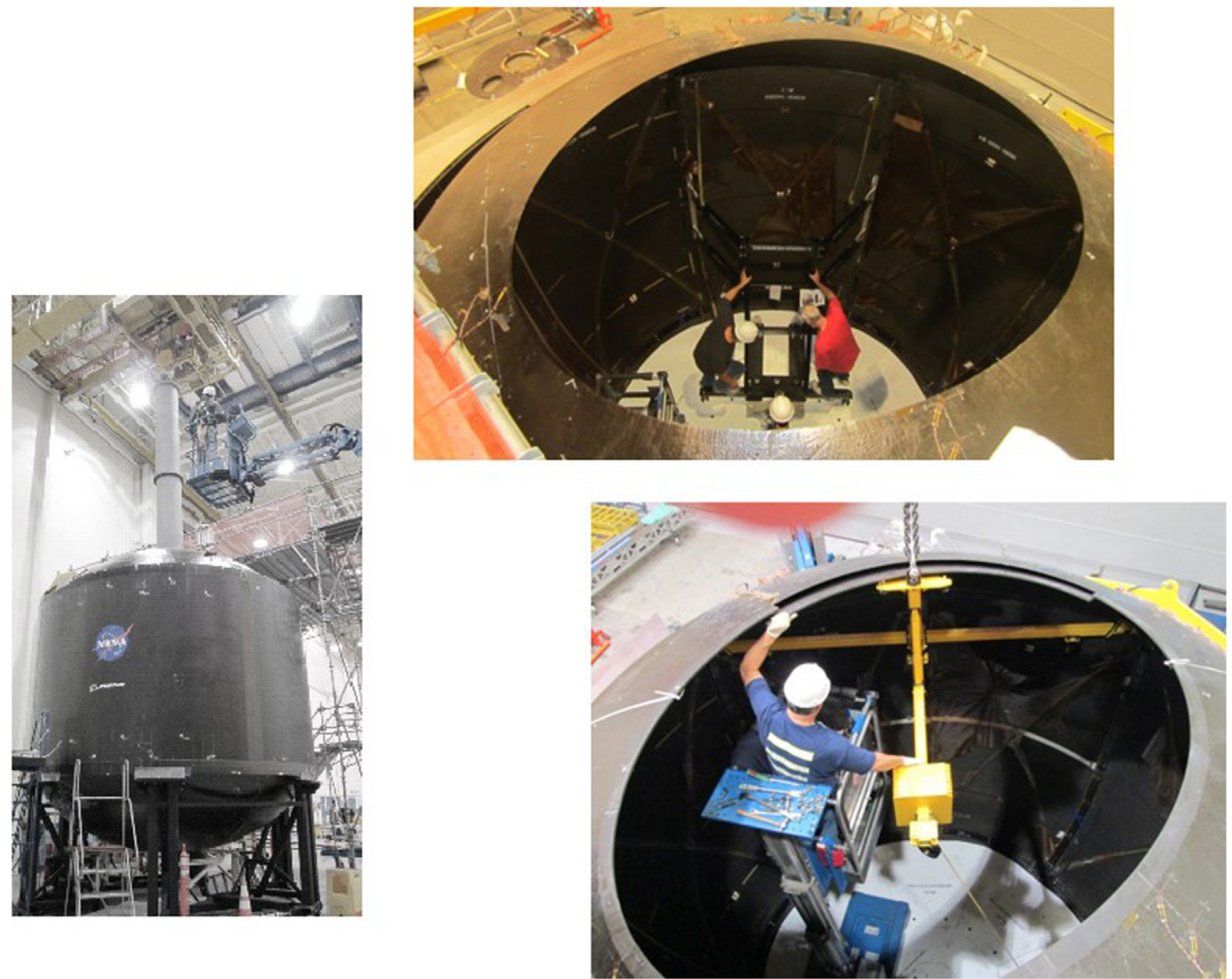

Fig. $275.5 \mathrm{~m}$ Tool extraction.

torque-limited bolts, Belleville washers, and Furon seals. Prior to shipping, the tank was instrumented and helium leak tested. Instrumentation consisted of $\mathrm{AE}$ sensors, temperature sensors and strain gages. Like the $2.4 \mathrm{~m}$ tank, with the goal of designing tanks to minimally-detectable-impact tensile strength properties (rather than to conservative open-hole strength allowables) and to monitor for damage during build and transport activities, the $5.5 \mathrm{~m}$ tank was fitted with an AE sensor-based SHMS. This system was installed after the initial tank shell cure and was kept active whenever practical during the build process.

The $5.5 \mathrm{~m}$ tank was shipped from Seattle to Huntsville aboard NASA's Super Guppy turbine (SGT) (Fig. 29). A shipping fixture was designed and fabricated to support the tank horizontally via attachment to the finger rings. The fixture was considered flight support equipment and had to meet factors of safety for both flight and crash loads.

\section{Tank Testing}

Boeing completed hundreds of tests on basic composite materials, adhesives, laminates, impact-damaged laminates and joint test articles. Tests were conducted at ambient and cryogenic temperatures to determine physical and mechanical properties and hydrogen permeation rates under relevant thermal and mechanical loads. The results of the coupon and joint testing supported the design, analysis, manufacturing and test readiness for the 2.4 and $5.5 \mathrm{~m}$ cryotanks. Key results included the substantiation of micro-strain design limits as an allowable to enable a lightweight design and permeation resistance values that met upper stage liquid hydrogen $\left(\mathrm{LH}_{2}\right)$ tank requirements.

Before the 34-month CCTD program ended, both the 2.4 and $5.5 \mathrm{~m}$ tanks underwent full-scale, ground-based cyclical testing at cryogenic temperatures, including ambient and cryogenic pressure tests. Additional ground tests simulated pressurization plus flight loads and axial/shear mechanical loads were applied through the skirts on the $5.5 \mathrm{~m}$ tank. As a consequence of successful testing, TRL/MRL levels increased from 2-3 at the outset of the program to 5-6 at the completion of the program. The project produced the largest composite cryotank ever manufactured via RAFP, cured OoA and relevant environment tested. 

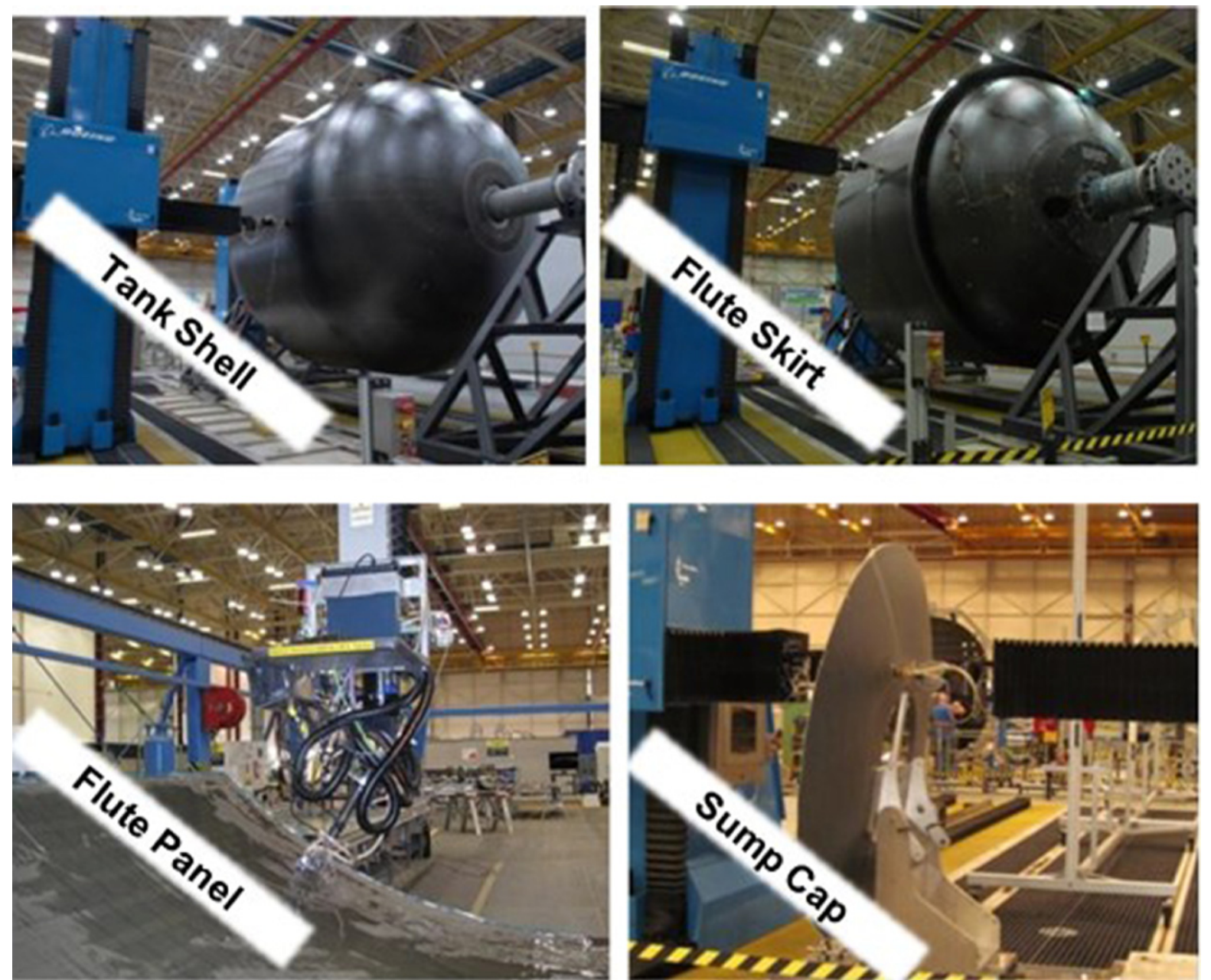

Fig. $285.5 \mathrm{~m}$ Tank nondestructive inspection (NDI).

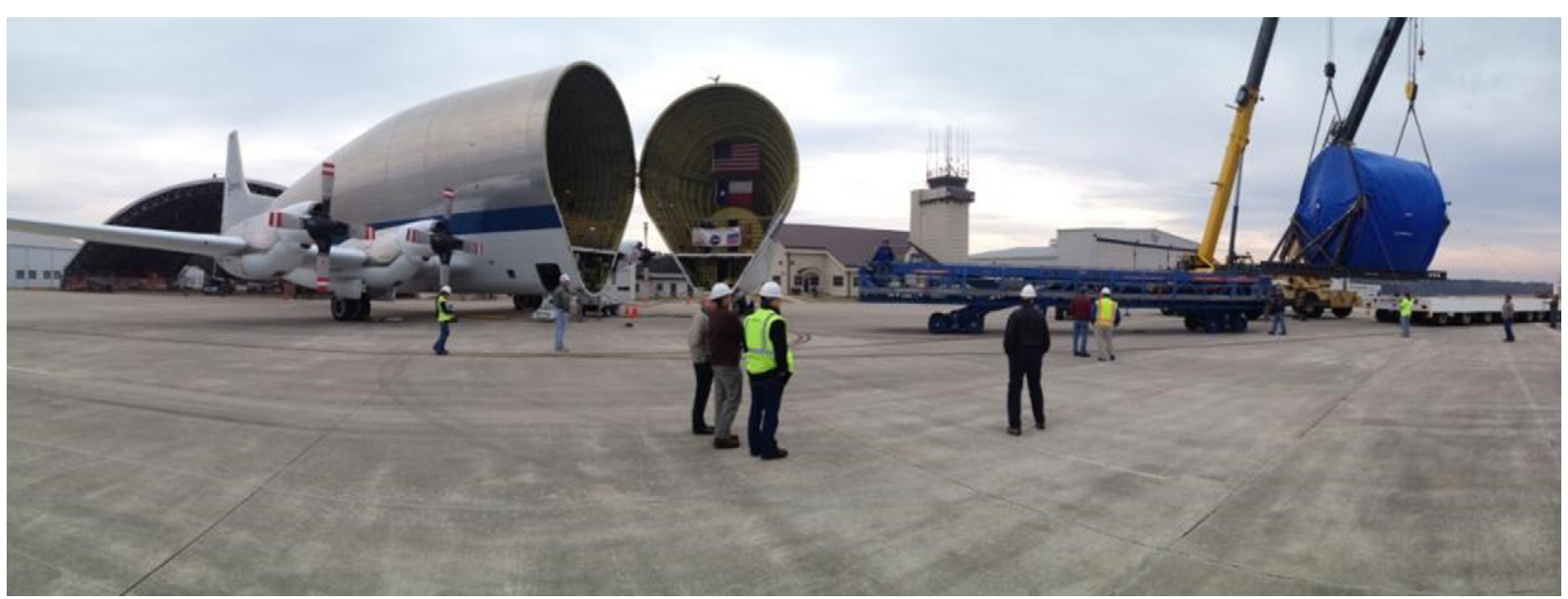

Fig. 295.5 m Shipping on Super Guppy.

\subsection{Test Criteria and Goal}

The cryotank tests were deemed to be successful when the following criteria were satisfied:

1. No evidence of catastrophic structural failure during ambient pressure test. 
2. No detrimental yielding, delamination, local disbonding of the laminate, or bonded joint failure occurring at or below the defined test pressure test level. Detrimental yielding was defined as any permanent deformation of the structure sufficient to affect the function of the part (such as excessive leakage or tank rupture) and/or completion of the test program.

Test goals were distinct from test success criteria. In addition to the above test success criteria, the following test goal was identified.

1. Pressure test strain data should correlate with predicted finite element model (FEM) strain data.

\subsection{Test Results}

The $2.4 \mathrm{~m}$ tank had a $1.9 \mathrm{~m}$ skirt length and overall volume of $7916 \mathrm{~L}$. It used $0.64 \mathrm{~cm}$ thick monocoque skirts to facilitate handling and to contain cost when compared to tooling and building fluted core skirts.

Tests on the $2.4 \mathrm{~m}$ tank were conducted at Test Cell 4626 at NASA MSFC. Although a temporary metallic shelter was used to protect the test article from wind and rain, actual testing was performed uncovered on a concrete apron (Fig. 30).

As a building block article, the $2.4 \mathrm{~m}$ tank was designed to have features traceable to the $5.5 \mathrm{~m}$ tank (Table 1).

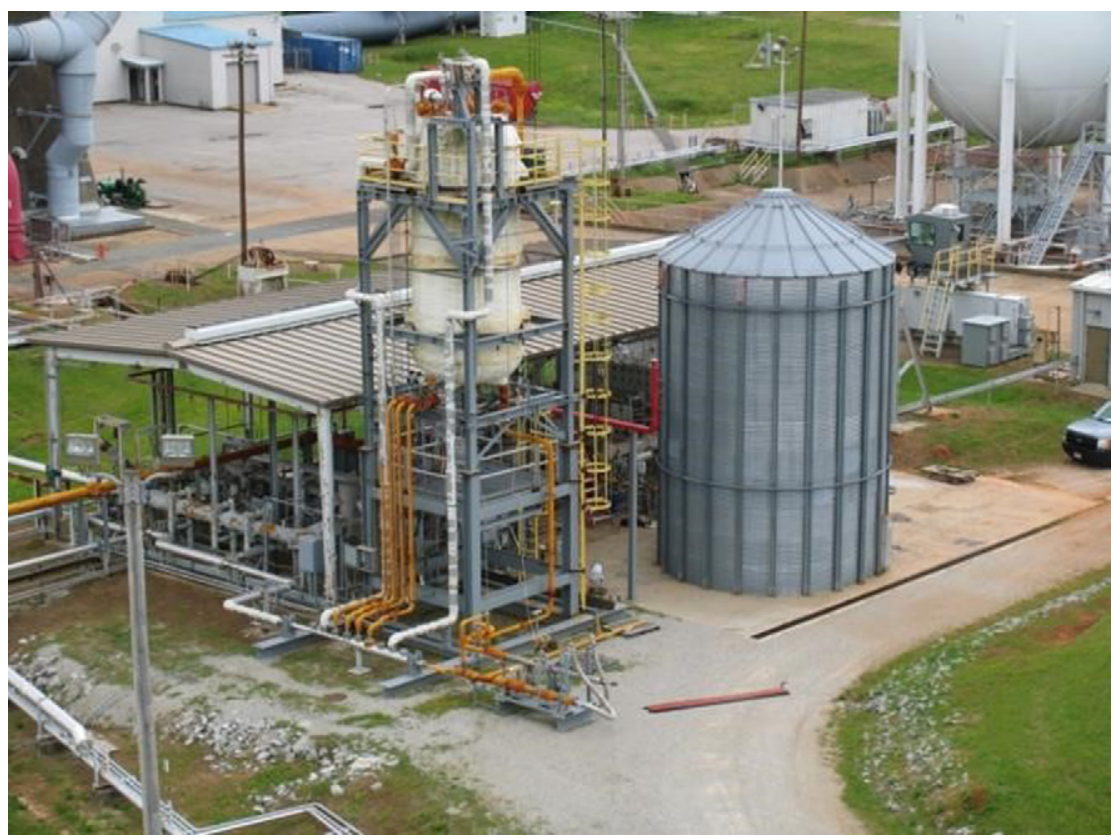

Fig. $302.4 \mathrm{~m}$ Test silo housing on test cell 4626 concrete apron.

Table 1 Traceability of $2.4-5.5 \mathrm{~m}$ tank

\begin{tabular}{lll}
\hline Feature & $5.5 \mathrm{~m}$ Cryotank & $2.4 \mathrm{~m}$ Precursor tank \\
\hline Diameter & $5.5 \mathrm{~m}$ & $2.4 \mathrm{~m}$ \\
$\begin{array}{l}\text { Wall construction } \\
\text { Laminate material }\end{array}$ & $\begin{array}{l}\text { Fluted core } \\
\text { Carbon/epoxy out-of-autoclave (OoA) material, } \\
\text { mixed ply thickness }\end{array}$ & $\begin{array}{l}\text { Monocoque cylinder and skirts } \\
\text { Same material and ply layup }\end{array}$ \\
Nominal skin thickness & Wall: nominal to withstand loads & \\
& Domes: nominal to withstand loads & Same (with pressure scaled up to achieve same \\
y-joint & Optimized softening strip & stresses in tank joints) \\
Skirt end joint & Load-bearing design & Baseline joint design at time of design freeze \\
Sump joint & Flight-representative joint with sealing & No skirt end joint; skirts built up for ease of handling \\
& characteristics & Same joint design \\
Access openings & Two 30-in-clear-diameter access openings & One 18-in-clear-diameter access opening at sump; \\
Tank shell mandrel concept & integrated in design & forward dome close-out, bonded with scarf joint \\
& Segmented breakdown tool (estimated 20 & Segmented breakdown tool (estimated 24 segments) \\
Structural health monitoring & segments) & Same design (20 sensors required) \\
(SHM) system & Acoustic sensor system & Same design \\
Scarf joints & Included at forward and aft domes & \\
\hline
\end{tabular}


Table 2

General test outline and sequence

\begin{tabular}{ll}
\hline Test/NDE sequence & Description \\
\hline Ambient pressure test & Pneumatic test to 0.69 MPa \\
Cryogenic pressure test & Pneumatic test to 0.93 MPa with tank filled with $\mathrm{LH}_{2}$ \\
Design life-cycle test & Single tank fill/20 pressurizations to $0.69 \mathrm{MPa}$ \\
& Pneumatic test to 0.57 MPa with tank filled with $\mathrm{LH}_{2}$ \\
\hline
\end{tabular}

The maximum design pressure (MDP) differential (the differential pressure at the bottom of the tank including the resultant head pressure) was defined in the Government-Furnished Information (GFI 5.1) 2.4-m System Requirements Document. The MDP was selected to achieve moderately high design strain levels at limit load in the $2.4 \mathrm{~m}$ tank wall, as designed for in the $10 \mathrm{~m}$ reference tank. Because the composite wall thicknesses and laminate orientations in the $2.4 \mathrm{~m}$ tank were identical to the $10 \mathrm{~m}$ reference tank, the applied internal pressures had to be increased to account for the smaller radius of the $2.4 \mathrm{~m}$ tank. The tank proof pressure was defined as 1.05 times the MDP. The $2.4 \mathrm{~m}$ test outline and sequence is shown in Table 2.

Thermal and mechanical life-cycle pressure testing was used to demonstrate structural adequacy after exposure (i.e., no degradation in capacity to retain hydrogen during testing). For a flight vehicle, pressure cycles are accumulated through proof tests, aborted tests, launch preparations, wet dress rehearsals and unsuccessful (scrubbed) launch attempts. Thermal cycles are accumulated every time a tank is filled with a cryogen and then drained and allowed to warm. Derived from historical data on metallic tanks, a pressure cycle will not be accrued at a pressure below $25 \%$ of the design ultimate. The design ultimate pressure (DUP) for the $2.4 \mathrm{~m}$ tank, used a uniform material ultimate design factor (UDF) of 1.5.

In-situ permeation measurements of isolated volumes of the $2.4 \mathrm{~m}$ tank were performed at designated pressure load increments. The two isolated volumes used for measurement of gaseous hydrogen $\left(\mathrm{GH}_{2}\right)$ permeation through the composite laminate were from sections of the aft dome and the lower y-joint plenum. On the aft dome, a metalized foil bag was bonded to the surface of the tank, underneath the Versafoam thermal insulation.

In June of 2013, the $2.4 \mathrm{~m}$ tank was successfully pressure tested at NASA MSFC. The test met program requirements: (1) stepwise fill with $\mathrm{LH}_{2}\left(-253^{\circ} \mathrm{C}\right)$ to $90 \%$ volume capacity and (2) MDP. The $2.4 \mathrm{~m}$ tank was then cycled through 20 pressure/vent cycles, during which time hydrogen gas permeation was measured.

Chilled high-purity helium carrier gas was flowed into the bag under slight positive pressure. Carrier gaseous helium (GHe) mixes thoroughly with any permeating hydrogen, after a steady-state condition is reached. Samples of the outlet gas were routed to and collected in lecture gas sample bottles that were located near the test cell. These gas sample bottles, containing the effluent gas, were taken to a chemical laboratory for gas chromatograph analysis and were subsequently used to estimate the hydrogen permeation rate.

The $2.4 \mathrm{~m}$ tank test provided significant building block learning that was later applied to testing the $5.5 \mathrm{~m}$ tank, including the following:

1. It was a trailblazer activity that helped improve understanding of as built performance.

2. It helped develop methodologies to minimize thermal gradients in the tank as it was being pressurized.

3. It pointed out that a more accurate method of measuring the liquid $\mathrm{H}_{2}$ level was needed. Cryogenic linear temperature sensors (CLTS) with improved accuracy at cryogenic temperatures were therefore used on the $5.5 \mathrm{~m}$ tank.

4. The test activity was crucial for providing rationale for subsequent $5.5 \mathrm{~m}$ test methodologies and scope.

The $5.5 \mathrm{~m}$ tank was transported to the NASA MSFC via the Supper Guppy wide body cargo aircraft in early 2014. A summary of $5.5 \mathrm{~m}$ tank test activities is shown in Table 3.

Testing began with an ambient pressure test to identify potential tank permeation locations and to evaluate if test facility piping and bolted joints could hold pressure with no leakage (Fig. 31). The tank was pressurized with gaseous nitrogen $\left(\mathrm{N}_{2}\right)$ during ambient testing. Bubble soap was applied to key surfaces. Pressure was held for $30 \mathrm{~min}$ and MSFC technicians verified that no leakage at bolted joints occurred, which in turn, verified that the facility was ready for the ambient pressure test.

Next, the tank was removed from the test stand and fully insulated. It was then trial fit and shimmed as necessary prior to bolting the load ring to the forward finger-ring of the load introduction fixture. Load actuators and shear actuators were installed. Finally, a roof was installed over the tank and cryogenic plumbing and permeation measurement system components were installed/finalized. Final pretest integration also included installation of transducers and facility leak checks devices, pressure line checkout and strain gage functionality check-out. Tank and y-joint purges were conducted and leak checks performed on facility piping.

To achieve the designated 20 cycles per life as defined by NASA in the GFI 5.1, the tank was filled with $\mathrm{LH}_{2}$ and the pressure was increased between 10 and 100\% MDP 20 times. For this application a 100\% full tank still retains an ullage volume of approximate $10 \%$ of the total tank volume.

For the life-cycle test, once the tank was filled with $\mathrm{LH}_{2}$, it was pressurized with $\mathrm{GH}_{2}$ at a rate of $0.09-0.23 \mathrm{~kg} / \mathrm{s}$. Because the $2.4 \mathrm{~m}$ tank had already been pressure tested to MDP, no real-time data review was required as the internal pressure was repeatedly increased and relieved. However, strain data was continually recorded so that it could be reviewed in the event of a test anomaly. After the 20th pressurization cycle, the tank was pressurized to MDP and in-situ permeation measurements were repeated. 
Table 3

5.5 m Tank test summary

\begin{tabular}{|c|c|c|c|}
\hline Testing summary & Date & Type & Details \\
\hline $\begin{array}{l}\text { Ambient pressure test (nitrogen }\left(\mathrm{N}_{2}\right) \text { ) was } \\
\text { successfully conducted }\end{array}$ & $5 / 22 / 2014$ & Ambient $\left(\mathrm{N}_{2}\right)$ & $\begin{array}{l}\text { Achieved target pressure and reached } 80 \% \text { of tarqet } \\
\text { strain }\end{array}$ \\
\hline $\begin{array}{l}\text { Liquid hydrogen }\left(\mathrm{LH}_{2}\right) \text { cryogenic pressure } \\
\text { test was successfully conducted }\end{array}$ & $7 / 20 / 2014$ & Cryogenic $\left(\mathrm{LH}_{2}\right)$ & $\begin{array}{l}\text { Achieved pressure and } 100 \% \text { of strain in the forward } \\
\text { dome acreage (permeation samples taken) }\end{array}$ \\
\hline $\begin{array}{l}\text { Combined ambient pressure }\left(\mathrm{N}_{2}\right) \text { and load } \\
\text { test was successfully conducted }\end{array}$ & $7 / 30 / 2014$ & Ambient $\left(\mathrm{N}_{2}\right)$ & $\begin{array}{l}\text { Achieved } 100 \% \text { desired pressure with } 100 \% \text { load on the } \\
\text { tank }\end{array}$ \\
\hline $\begin{array}{l}\mathrm{LH}_{2} \text { combined cryogenic pressure and load } \\
\text { test was performed }\end{array}$ & $8 / 16 / 2014$ & Cryogenic $\left(\mathrm{LH}_{2}\right)$ & $\begin{array}{l}\text { The test was prematurely stopped at } 20 \% \text { mechanical } \\
\text { loads due to mechanical issues with applying the loads } \\
\text { in the test facility (permeation samples taken) }\end{array}$ \\
\hline $\begin{array}{l}\mathrm{LH}_{2} \text { cryogenic pressure cycle test was } \\
\text { successfully conducted }\end{array}$ & $8 / 17 / 2014$ & Cryogenic $\left(\mathrm{LH}_{2}\right)$ & $\begin{array}{l}\text { Achieved our goal of } 80 \text { pressure cycles }(20-90 \% \max \\
\text { pressure) on the tank (permeation samples taken) }\end{array}$ \\
\hline $\begin{array}{l}\text { Permeation with gaseous hydrogen }\left(\mathrm{GH}_{2}\right) \\
\text { test was conducted }\end{array}$ & $8 / 22 / 2014$ & Ambient $\left(\mathrm{GH}_{2}\right)$ & $\begin{array}{l}\text { Achieved desired pressure. Issues with a leak in facility } \\
\text { piping and a leak in the bag prevented any useful } \\
\text { permeation data }\end{array}$ \\
\hline Permeation with $\mathrm{GH}_{2}$ test was conducted & $8 / 28 / 2014$ & Ambient $\left(\mathrm{GH}_{2}\right)$ & Achieved desired pressure Obtained permeation data \\
\hline
\end{tabular}

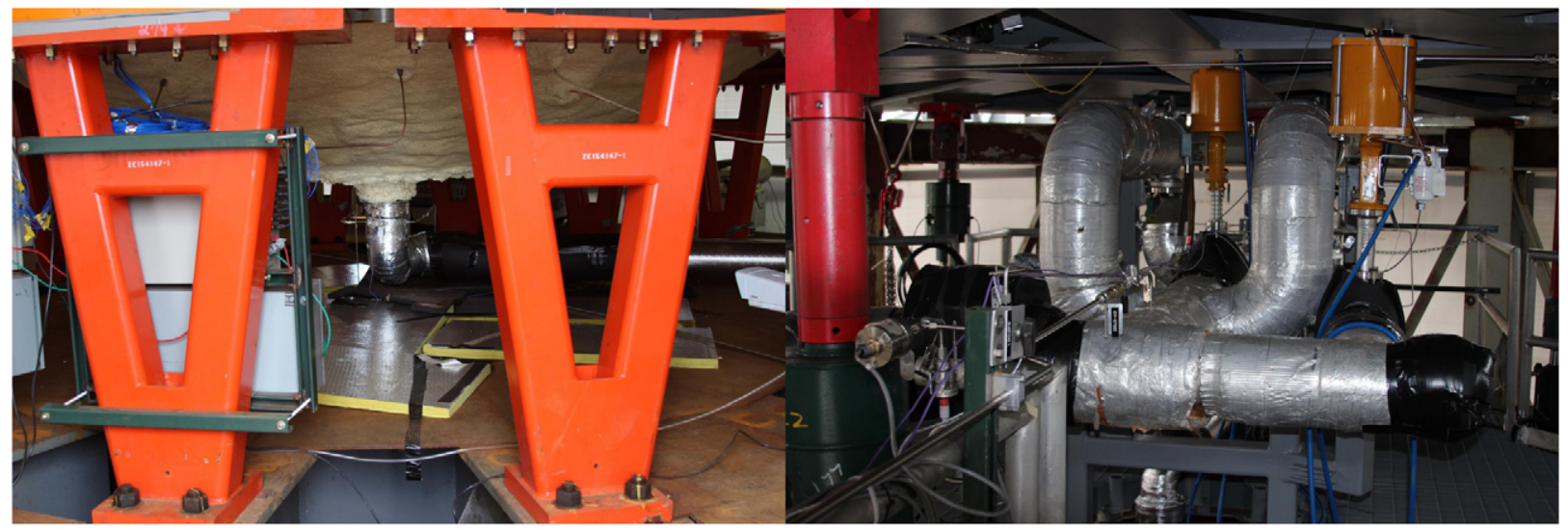

Fig. $315.5 \mathrm{~m}$ Ambient pressure test configuration.

During the cryogenic test, boil-off was lower than expected and it was recommended that performance should be reviewed to reduce $\mathrm{LH}_{2}$ procurements and the need for auxiliary tanks for subsequent testing. Prediction of the boil off was determined to be difficult and actual measurement during the test illustrated this limitation. The test was deemed to be successful based on preestablished success criteria. However, it was noticed that the in-situ permeation bag cracked during test so it was assumed that some of the permeation data was compromised. Post-test calibration of the permeation measurement system indicated that both bag volumes were breached sometime during the pressure test. The measured permeation data was still estimated and were below the permeation measurement set by the test success criteria.

$\mathrm{LH}_{2}$ testing caused ice to gather on the test stand. Once the tank was depressurized, the ice melted and leaked into the y-joint. The incident caused the test to be postponed in order to dry the joint. Standing water was removed using $0.064 \mathrm{~cm}$ diameter Tygon tubing attached to a vacuum and final drying was accomplished with a gaseous He (GHe) purge.

A combined ambient pressure and load test, using gaseous $\mathrm{N}_{2}$, was conducted to demonstrate ability of the $5.5 \mathrm{~m}$ tank to withstand a preestalished internal pressure and axial/shear mechanical loads to the maximum tension and compressive limit loads. It should be noted that analytically this case was identified as the tank's critical load case with the lowest test margin.

After successful mechanical loads and pressure influence pretest, to ensure that loads were being properly applied to the structure, testing was initiated. The $5.5 \mathrm{~m}$ tank was pressurized to a preestalished internal pressure with gaseous $\mathrm{N}_{2}$ before applying any loads. The tank was taken to $100 \%$ load with this pressure and then pressure was reduced to demonstrate the maximum compression condition.

The CCTD project established a permeation goal based on a long duration lunar lander mission. The permeation rates and micro-strain levels for all the tests of both tanks were recorded against a background of the maximum allowable permeation rates for common tank applications. At the maximum test strain, the permeation performance was estimated to be slightly above the lunar lander goal, but well within the allowable for an upper stage or booster stage tank applications. 


\section{Future Recommendations}

Composite cryotank evolution has been hampered by short development schedules, limited building block activities, tight budgets, cost overruns and program cancelations. The CCTD program was significant in the fact that it executed a building block activity focused on systematically raising TRL/MRL from 2-3 to 5-6 by building and testing in a relevant environment. Several key technologies/designs were identified that can be incorporated into future flight hardware: (1) a y-joint softening strip for load transfer at cryo-temperatures, (2) thin ply uni-tape for permeation control, (3) fluted core for structural efficiency and venting, and (4) one-piece tank design for weight minimization. The next step for the industry is to facilitize demonstrated manufacturing processes (e.g., multipiece tools, RAFP, and large scale cure) and incorporate composite tanks into new long duration aircraft and launch vehicles. One potential near term project is the DARPAs Experimental Spaceplane (XS-1). XS-1 is being fielded in an effort to deploy small payloads into earth orbit at a cost much lower than current expendable launch systems. ${ }^{20}$

\section{Summary}

This chapter presented an overview of the NASA/Boeing CCTD program. In addition to providing a historical background, it provided details on the tooling and major manufacturing steps involved in the manufacture of a $2.4 \mathrm{~m}$ precursor and $5.5 \mathrm{~m}$ fullscale tank. Lessons learned from the tooling and build of the $2.4 \mathrm{~m}$ tank helped guide efforts to build the $5.5 \mathrm{~m}$ tank The tanks contained several unique design features (e.g., one-piece belly-bandless shell, extensive co-cures and co-bonds and fluted core skirt). The tooling system performed to expectations, accurately supporting layup operations and disassembling as prescribed through small openings. The bulk of the tank was laid up using a RAFP system. The RAFP system demonstrated the ability to meet out time constraints using thin and thick oven cure prepreg. Assembly of the $2.4 \mathrm{~m}$ tank was completed by Boeing in December of 2012 and the $5.5 \mathrm{~m}$ tank was completed in March of 2014. NASA Marshall spray-on foam insulated the tanks and conducted cyclic cryo-temperature high pressure testing.

The CCTD Phase 2 project achieved a goal of demonstrating a 25-30\% lower weight design traceable to a $10 \mathrm{~m}$ upper stage $\mathrm{LH}_{2}$ tank. The two all-composite cryotanks were designed, built, and tested within 30 months of contract start. Both tanks were subjected to cyclic $\mathrm{LH}_{2}$ filling and pressurization testing at NASA MSFC. Additionally, the $5.5 \mathrm{~m}$ tank was subjected to flight loads in combination with pressure loads. The minimum analytical structural margin was determined to be at the aft y-joint and occurred under thermal loading only. Stresses change minimally with added pressure and flight loads. Because the 2.4 and $5.5 \mathrm{~m}$ tanks responded well during $\mathrm{LH}_{2}$ fill, both tanks were pressurized after stable thermal loading. This may indicate the tanks had additional structural capability that was not accurately represented in the analysis. The tanks were successfully pressure tested to MDP and demonstrated safety factors at the scarf joints 1.5 and greater at design strain levels.

The project confirmed that composite cryotanks can achieve a 33\% weight savings compared to aluminum-lithium cryotanks, and it demonstrated permeation performance that meets the allowable for upper stage and boost stage applications. Technical risks of large-scale, $\mathrm{LH}_{2}$, composite cryotanks were substantially mitigated by demonstrating scalable manufacturing, moderately high strain design allowables, y-joint strength and permeation performance.

\section{References}

1. Fikes, J., Vickers, J., 2011. Composite cryotank technologies and demonstration project. In: 62nd Joint Army-Navy-NASA-Air Force Propulsion Meeting and Joint Meeting of the 10th Modeling \& Simulation Subcommittee (SPS), Huntsville, AL, December 5-9, 2011

2. NASA Press Release, 2014. Composite Cryotank Technologies \& Demonstration. Available at: https://ntrs.nasa.gov/archive/nasa/casi.ntrs.nasa.gov/20140016807.pdf (accessed 22.12.16).

3. Vickers, J., 2013. Composites Australia Conference composite cryotank projects Structures for launch vehicles. In: Composites Australia Conference and Trade Show, Melbourne, Australia.

4. Bauer, R.A., Millar, P.S., 2015. Bridging the technology readiness "valley of death" using nanosats. In: Ka and Broadband Communications Conference, National Aeronautics and Space Administration Goddard Space Flight Center Greenbelt, Maryland, Bologna, Italy, October 12-14, 2015.

5. Jackson, J.R., Vickers, J., Fikes, J., 2011. Composite cryotank technologies and demonstration phase I summary. National Space and Missile Materials Symposium Madison, Wisconsin, June 27-July 1, 2011.

6. Defense Science Board, 1992. Report of the Defense Science Board Task Force on National AeroSpace Plane (NASP). Available at: https://archive.org/stream/ ReportoftheDefenseScienceBoardTaskForceonNationalAeroSpacePlaneNASP/Report\%20of\%20the\%20Defense\%20Science\%20Board\%20Task\%20Force\%20on\%20National\% 20AeroSpace\%20Plane\%20NASP_djvu.txt (accessed 22.12.16).

7. Hartunian, B., 2006. McDonnell Douglas composite cryotanks - A personal history. Composites World. Available at: http://www.compositesworld.com/columns/mcdonnelldouglas-composite-cryotanks - a-personal-history

8. Dumbacher, D., 1996. Results of the DC-XA program. American Institute of Aeronautics and Astronautics Space Programs and Technologies Conference, Huntsville, AL.

9. Niedermeyer, M., 2000. X-33 L L 2 tank failure investigation findings. In: 4th Conference on Aerospace Materials, Processes, and Environmental Technology, Huntsville, AL.

10. Sullivan, R.B., Winters B., 1994. X-34 program overview. In: 34th AIAA/ASME/SAE/ASEE Joint Propulsion Conference and Exhibit, Joint Propulsion Conferences, Cleveland, $\mathrm{OH}$.

11. Pendleton, E., Clark, B., Griffin, K., 2012. Integrated composite structures demonstration for future space launch vehicle airframe applications. In: 53rd AIAA/ASME/ASCE/ AHS/ASC Structures, Structural Dynamics, and Materials Conference, Honolulu, HI.

12. Black, S., 2005. An update on composite tanks for cryogens. Composites World. Available at: http://www.compositesworld.com/articles/an-update-on-composite-tanks-forcryogens 
13. McKinney, B., Newton, K., 2003. Tests boosts confidence in using composite tanks for reusable launch vehicles. Northrup Grumman news release. Available at: http:// news.northropgrumman.com/news/releases/northrop-grumman-nasa-successfully-test-composite-hydrogen-fuel-tank-for-reusable-launch-vehicles (accessed 19.12.2003),

14. Robinson, M.J., 2006. Determination of allowable hydrogen permeation rates for launch vehicle propellant tanks. In: 47th AIAA/ASME/ASCE/AHS/ASC Structures, Structural Dynamics, and Materials Conference, Newport, Rhode Island.

15. McCarville, D., Ghose, S., Guzman, J.C., Sweetin, J.L., 2013. Manufacturing overview of a 2.4 m composite cryotank. In: SAMPE Technical Conference Proceedings, Long Beach, CA.

16. McCarville, D., Guzman, J.C., Dillon, A., Tidwell, R., Margraf, T., 2015. Smart tooling for fluted core composite cryotank and dry structure manufacture. In: Composite and Advanced Materials Expo, Dallas, TX.

17. McCarville, D., Guzman, J.C., Birkland, J.O., Tidwell, R.S., 2014. Fluted core skirt development for the composite cryotank technology development program. In: SAMPE Technical Conference Proceedings, Seattle, WA.

18. McCarville, D., Guzman, J.C., Rivera, D.E., et al., 2014. Manufacturing overview of the 2.4 \& 5.5 m composite cryotank. Manufacturing Problem Prevention Program the Aerospace Corporation, El Segundo, CA.

19. McCarville, D., Ghose, S., Guzman, J.C., Johnson, B., Pelham, L., 2014. Overview of the NASA 5.5 m composite cryotank technology development program. In: SAMPE Technical Conference Proceedings, Seattle, WA.

20. Sponable, J., 2016. Experimental spaceplane (XS-1): Aiming to reduce the time to space and cost to space by orders of magnitude. DARPA public release statement.

\title{
Further Reading
}

Glass, D.E., 2004. Airframe technology development for next generation launch vehicles. In: 55th International Astronautical Congress, Vancouver, Canada.

Mital, S.K., Geyekenyesi, J.Z., Arnolde, S.M., et al., 2006. Review of current state of the art and key design issues with potential solutions for liquid hydrogen cryogenic storage tank structures for aircraft applications, NASA/TM.

National Research Council, 1995. Reusable launch vehicle technology development and test program. In: Committee on Reusable Launch Vehicle Technology and Test Program Aeronautics and Space Engineering Board Commission on Engineering and Technical Systems. Washington, DC: National Academy Press.

Vickers, J.H., Fikes, J., Jackson, J.R., et al., 2012. NASA composite cryotank technology demonstration: Overview. In: SAMPE Technical Conference Proceedings, Baltimore, MD.

\section{Relevant Websites}

\author{
http://www.boeing.com/space/space-launch-system/ \\ Boeing. \\ https://www.cytec.com/sites/default/files/files/CYT_12000_COLLECT_BROCH-CYCOM_5320-1.pdf \\ CYCOM. \\ http://www.nasa.gov/offices/oct/stp/game_changing_development/index.html \\ NASA. \\ https:/Www.nasaspaceflight.com/2016/07/darpa-pushing-experimental-spaceplane-xs-1/ \\ NASA SPACEFLIGHT.COM.
}

